Document downloaded from:

http://hdl.handle.net/10251/137883

This paper must be cited as:

Salas, J.; Yepes, V. (2019). MS-ReRO and D-ROSE methods: Assessing relational uncertainty and evaluating scenarios risks and opportunities on multi-scale infrastructure systems. Journal of Cleaner Production. 216:607-623. https://doi.org/10.1016/j.jclepro.2018.12.083

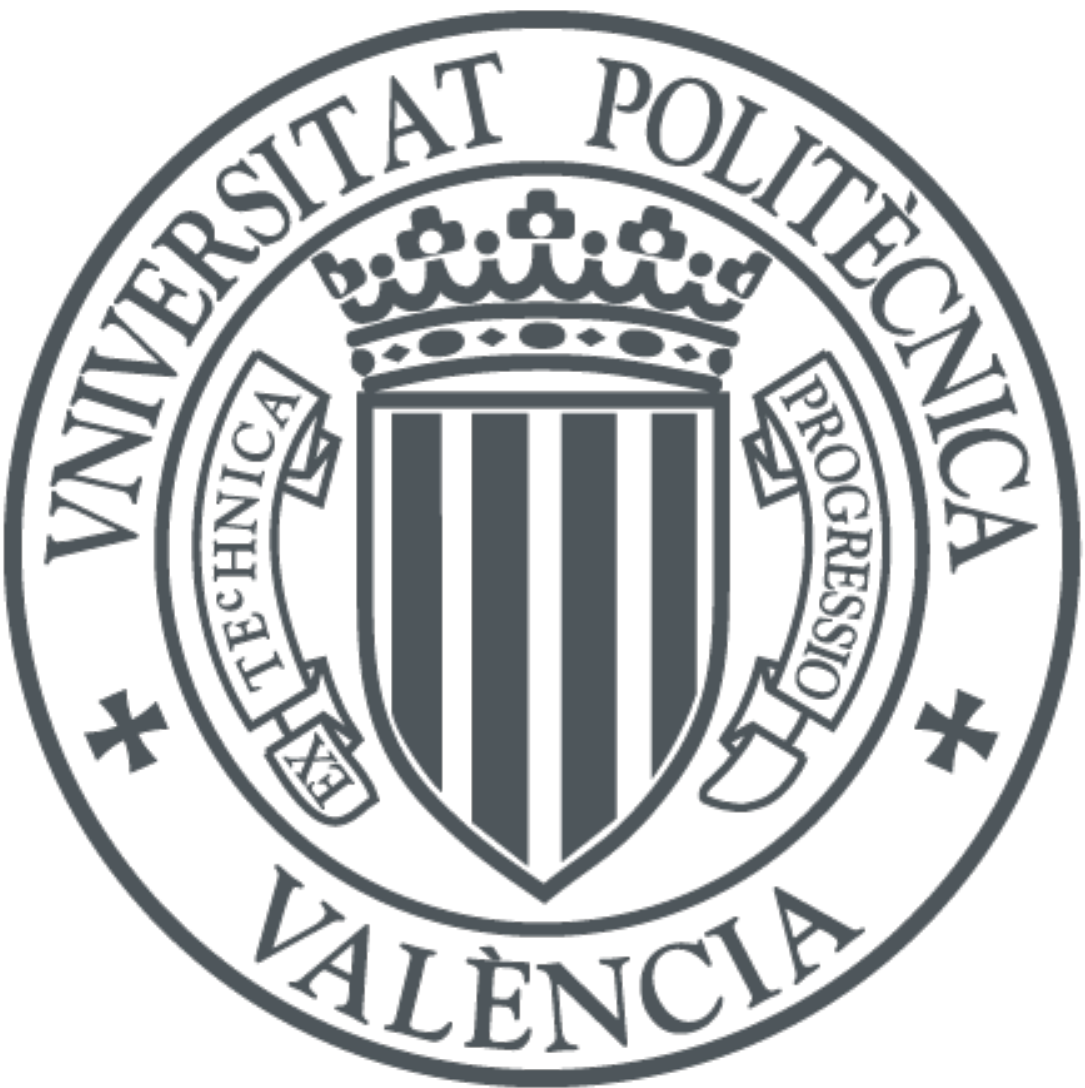

The final publication is available at

https://doi.org/10.1016/j.jclepro.2018.12.083

Copyright Elsevier

Additional Information 


\title{
MS-ReRO and D-ROSE methods: assessing relational uncertainty and evaluating scenarios' risks and opportunities on multi-scale infrastructure systems.
}

\author{
Jorge Salas $^{1}$ \\ Víctor Yepes ${ }^{2}$
}

\section{Abstract}

There is a growing interest in model-based decision support systems contributing to strategic planning. The application of these in the case of urban infrastructure planning requires methods specifically aimed at addressing the relational uncertainties arising from the complex, multi-scale nature of this field. This study presents UPSS, a comprehensive urban planning support system integrating the generation of planning alternatives, the evaluation of alternatives under a set of relevant scenarios selected dynamically in a cognitive way, and the proposal of policies to accompany the planning alternative. For this purpose, UPSS integrates two novel methods which deal respectively with the ex post identification of relevant scenarios for the evaluation of the vulnerability and resilience of the alternatives, and with the assessment of relational uncertainty. According to the risks and opportunities borne by the system, the process makes it possible to select an infrastructure plan to alleviate the problem of urban vulnerability, as well as a set of relational contracts for its proper implementation across the different governmental scales of the infrastructure system. The whole process is tested via a case study, in which USPP first proposes optimal urban infrastructure plans that contribute to ameliorate the problem of urban vulnerability in Spain, then evaluates the risks and opportunities attached to the planning alternatives, and finally presents sets of policy measures to accompany the implementation of the alternative selected.

Keywords: Urban vulnerability; infrastructure planning; multi-scale; risk; opportunity; relational uncertainty.

\footnotetext{
${ }^{1}$ School of Civil Engineering, Universitat Politècnica de València, 46022 Valencia, Spain. Corresponding author. Phone+34963879563; fax: +34963877569; e-mail: jorsaher@doctor.upv.es

2 Professor, ICITECH, Universitat Politècnica de València, 46022 Valencia, Spain. Phone +34963879563; fax: +34963877569; e-mail: vyepesp@cst.upv.es 


\section{Introduction}

Both urban strategic planning (USP) and urban vulnerability assessment (UVA) demand comprehensive approaches that integrate methods to address key issues identified for an effective USP (Malekpour et al., 2015). These issues are connected with current UVA research by Salas and Yepes (2018a) (Table 1), who proposed a decision framework for selecting UVA models that fulfill these requirements (2018b), including the ability to monitor and anticipate vulnerability, which "would be a public good for all potentially affected places and systems” (Stern et al., 2013, p. 609).

\begin{tabular}{|c|c|c|c|c|c|c|c|c|}
\hline \multirow{3}{*}{ Method } & \multirow{3}{*}{$\begin{array}{l}\text { Multi- } \\
\text { Criteria } \\
\text { assess. }\end{array}$} & \multicolumn{7}{|c|}{ Characteristics } \\
\hline & & \multirow{2}{*}{$\begin{array}{c}\text { Strategic/Mu } \\
\text { lti-Objective } \\
\text { capacity }\end{array}$} & \multirow{2}{*}{$\begin{array}{l}\text { Partici- } \\
\text { patory }\end{array}$} & \multirow{2}{*}{$\begin{array}{l}\text { Cogni- } \\
\text { tive }\end{array}$} & \multicolumn{2}{|c|}{$\begin{array}{l}\text { Uncertainty- } \\
\text { Scen. Analysis }\end{array}$} & \multirow[t]{2}{*}{$\begin{array}{l}\text { Comprehen. } \\
\text { Assessment }\end{array}$} & \multirow{2}{*}{$\begin{array}{r}\text { Multi-Scale } \\
\text { P-A (*) }\end{array}$} \\
\hline & & & & & Risk & Opport. & & \\
\hline UVAM method $(* *)$ & $\checkmark$ & $\checkmark$ & $\checkmark$ & $\checkmark$ & $\checkmark$ & $\checkmark$ & $\checkmark$ & $\checkmark$ \\
\hline AST & $\checkmark$ & & $\checkmark$ & & & & & $\checkmark$ \\
\hline APST & $\checkmark$ & & $\checkmark$ & & & & & \\
\hline IPSS & $\checkmark$ & & $\checkmark$ & & & & $\checkmark$ & \\
\hline $\begin{array}{l}\text { UPSS (Method } \\
\text { proposed) }\end{array}$ & $\checkmark$ & $\checkmark$ & $\checkmark$ & $\checkmark$ & $\checkmark$ & $\checkmark$ & $\checkmark$ & $\checkmark$ \\
\hline
\end{tabular}

Table 1 Characteristics demanded for an effective urban strategic planning:

This ability can help to solve the resource-allocation problems faced by urban planning when dealing with urban vulnerability (UV) (King and Blackmore, 2013) by providing prioritization guidelines for its implementation (Nahiduzzaman et al., 2015). The European Union, for example, has allocated major resources to programs aiming to deal with UV, such as the URBAN I and URBAN II projects. These programs have together mobilized up to $€ 3.380$ millions of total investment, spread across 188 urban projects (Table 2) selected from proposals submitted by 15 countries. This entailed a decisionmaking process, from the proposal of candidate projects for these programs to the selection of those that were finally awarded ERDF funds, in which different aspects of UV played a key role (Hurtado, 2012). In the case of Spain, however, the lack of a UVA method common to all candidates (Hurtado, 2012), the lack of a comprehensive approach enabling an understanding of the interrelated trends in UV (Hurtado, 2017), and the absence of a multi-scale assessment framework to provide an integrated evaluation of entities at the three relevant levels of government (Central Government, regions, and cities) (Hurtado, 2017), has led to failures in the allocation of the resources committed 
(Hurtado, 2012).

\begin{tabular}{|c|c|c|c|c|c|c|c|}
\hline \multirow[b]{2}{*}{ Program } & \multirow[b]{2}{*}{ Time Span } & \multicolumn{3}{|c|}{ EU $(*)$} & \multicolumn{3}{|c|}{ SPAIN (*) } \\
\hline & & $\begin{array}{l}\mathrm{N}^{\circ} \text { Urban } \\
\text { programs }\end{array}$ & $\begin{array}{c}\text { ERDF } \\
\text { contribution } \\
\text { (Mio } €)\end{array}$ & $\begin{array}{c}\text { Total } \\
\text { investment } \\
(\text { Mio } €)\end{array}$ & $\begin{array}{l}\mathrm{N}^{\circ} \text { Urban } \\
\text { programs }\end{array}$ & $\begin{array}{c}\text { ERDF } \\
\text { contributio } \\
n(\text { Mio } €)\end{array}$ & $\begin{array}{c}\text { Total } \\
\text { investment } \\
(\text { Mio } €)\end{array}$ \\
\hline URBAN I & 1994-1999 & 118 & 900 & 1,800 & 30 & 152 & 235 \\
\hline $\begin{array}{l}\text { URBAN II } \\
\text { Iniciativas }\end{array}$ & 2000-2006 & 70 & 728 & 1,580 & 10 & 120 & 260 \\
\hline Urbanas $(* *)$ & 2007-2013 & - & - & - & 70 & 344 & 542 \\
\hline TOTAL & 1994-2013 & 188 & 1,628 & 3,380 & 40 & 272 & 495 \\
\hline $\begin{array}{l}\left(^{*}\right) \text { Retrieved } \\
1994-1999 \text { an } \\
(* *) \text { Spanish } \\
\text { program }\end{array}$ & $\begin{array}{l}\text { European U } \\
0-2006\end{array}$ & on, Regiol & Policy. Ex-1 & t Evaluatio & he URBA & Community & \\
\hline
\end{tabular}

Table 2 Investment on URBAN programs and ERDF support allocation

\section{Planning support systems for urban vulnerability}

Several previous efforts have been made to tackle the problem of UV through infrastructure planning (Table 1). AST was developed by Voskamp and Van de Ven (2015) as a planning support system () enabling collaborative planning that provided the users with site-specific sets of blue-green measures to handle flooding, drought and heat stress vulnerability for a particular urban reconstruction project, from which it was possible to assess a planning option across several scales. The APST method, in turn, was proposed by Van de Ven et al. (2016) to provide sets of adaptation measures, the effectiveness of which is evaluated in terms of drought control, heat stress reduction, quality of water and average costs of construction and management. Finally, investment decisions can be informed by means of the IPSS (Schweikert et al., 2014), a providing a range of information including the construction, maintenance and adaptation costs of a comprehensive road infrastructure within an area, given several climate change scenarios.

All these methods, however, showed important shortcomings in the achievement of an effective USP. These included the lack of the strategic capacity required both to propose multi-objective optimal solutions, and to enable decision-makers to extract knowledge from the relations between the criteria used to assess urban infrastructure plans (UIPs) (Table 1). In addition, the frameworks analysed failed to assess infrastructure systems across the multiple political-administrative scales, and they were limited to evaluating scenarios without deriving any probabilities or impacts. This rendered them unsuitable for analysing alternatives in terms of the risks and opportunities attached to them (Table 1). While these issues have been addressed for UVA in previous work (Salas and Yepes, 2018b), a method for integrating them is still pending for generating UIPs to ameliorate the problem of UV. 
Following the discursive approach previously employed for the generation and selection of UVA models (2018b), this paper overcomes the existing limitations by means of the Urban Planning Support System (UPSS), an integrative in which these issues are addressed by multi-objective optimization (MOO) for the generation of planning alternatives. By means of the D-ROSE method, the alternatives are then evaluated under a range of scenarios that have been found by decision-makers (DMs) to be relevant, in terms of risks and opportunities (Fig. 1). Once a planning alternative has been selected, the analysts are able, through MS-ReRO, to determine the set of accompanying policy measures, in the form of relational contracts between the multiple governmental scales. This offers better prospects for proper implementation of the infrastructure plan selected across the multiple political-administrative layers of the system.

\section{Scenario Analysis}

Scenarios can be defined as the different states of the world (SOW) that may affect a decision's outcome, where the states of the world are represented by combinations of values that the set of exogenous variables can adopt (Kasprzyk et al., 2013). In contrast to ex ante approaches, in ex post methods (Table 3) the scenarios are generated parametrically or stochastically by varying the data of the exogenous variables. In this way, the analyst can observe how changes in these scenarios, i.e. in their policy assumptions, may affect the performance of their planning strategies, and identify scenarios ex post according to the risks or the opportunities that they present (Ray \& Brown, 2015). Unlike other proposals (Table 3), in the Dynamic Risks and Opportunities Simultaneous Evaluation (D-ROSE) method, analysts are enabled to ex post delineate relevant scenarios by dynamically setting up the relevant (vulnerability and resilience) criteria, from where the risks and opportunities of the scenarios and alternatives are simultaneously evaluated (Fig. 1).

\begin{tabular}{|c|c|c|c|c|c|c|c|}
\hline \multicolumn{2}{|c|}{ Characteristics: } & \multirow[t]{2}{*}{ Info-Gap } & \multirow{2}{*}{$\frac{\mathrm{RDM}}{\checkmark}$} & \multirow{2}{*}{$\frac{\text { DAPP }}{\checkmark}$} & \multirow{2}{*}{$\begin{array}{c}\text { Decision Scaling } \\
\checkmark\end{array}$} & \multirow{2}{*}{$\frac{\text { D-ROSE }}{\checkmark}$} & \multirow{2}{*}{$\frac{\text { MS-ReRO }}{\checkmark}$} \\
\hline Scen. & Failure(Worst) & & & & & & \\
\hline Identification & Windfall(Best) & $\checkmark$ & & & & $\checkmark$ & $\checkmark$ \\
\hline \multirow{2}{*}{ Dynamics } & Time & & & $\checkmark$ & & & \\
\hline & P-A $(*)$ & & & & & $\checkmark$ & $\checkmark$ \\
\hline \multirow{2}{*}{ Multi-Scale } & Time & & & & & & \\
\hline & P-A $(*)$ & & & & & $\checkmark$ & $\checkmark$ \\
\hline \multirow{2}{*}{ Relevant Scen. } & Ex Ante & & $\checkmark$ & & & & \\
\hline & Ex Post & & & & & $\checkmark$ & $\checkmark$ \\
\hline \multirow{4}{*}{ Scen. Trade-offs } & Vars/Scen & & $\checkmark$ & & $\checkmark$ & & \\
\hline & Alt/Scen & $\checkmark$ & & & & $\checkmark$ & \\
\hline & Risk/Opp & & & & & $\checkmark$ & \\
\hline & Multi-Obj & & $\checkmark$ & & & $\checkmark$ & \\
\hline
\end{tabular}




\section{Multi-scale dimension of infrastructure systems: problem and solution}

Infrastructure systems are spatially and functionally interdependent multi-scale hierarchical systems (Johansson \& Hassel, 2010) where entities are affected by subentities, which enable bottom-up cascade-failure (Eusgeld et al., 2011). Infrastructure planning, in consequence, is affected by this multi-level and complex nature (Frank \& Martínez-Vázquez, 2015), should consider inter-scale relationships in methods attempting to evaluate uncertainty (Sierra et al., 2017), and capture system's ability to adapt to failures of sub-entities (Eusgeld et al., 2011). Several policy options have been defined to address this challenge, all of which pursue the improvement of the overall performance (Charbit \& Michalun, 2009). However, there is a lack of integral infrastructure planning and investment strategies that take overall performance into account (Charbit \& Gamper, 2015) and measure impacts at the overall (system-ofsystems) scale (Eusgeld et al., 2011), which has led to failures of co-ordination among scales that need to be mitigated (Frank \& Martínez-Vázquez, 2015).

The method presented aims to bridge this gap by means of a relational system that implements relational contracts between governmental scales. In the Multi-Scale Relational Risks and Opportunities (MS-ReRO) scenario module (Fig. 1), the behaviour of infrastructure plans is evaluated across the range of possible configurations of relational contracts (Frank \& Martínez-Vázquez, 2015), and optimal policy strategies are proposed to minimize the risks while maximizing the opportunities associated with interscale coordination.

The remainder of this paper is organized as follows. In the methods section, the planning process framework is described and the framework's theoretical foundations are explained in detail. In the case study section, the methods presented are illustrated by an exercise in which the methodology proposed is applied to an actual case, and the results are presented in the subsequent section. The method is then analysed and compared in the discussion section to show its efficacy. Finally, general conclusions are drawn in the closing section.

\section{Methods}


This section describes the whole process, analysing its elements one by one as indicated in Fig. 2. First is a description of how the process works in general; then, for each step, detailed explanations are given.

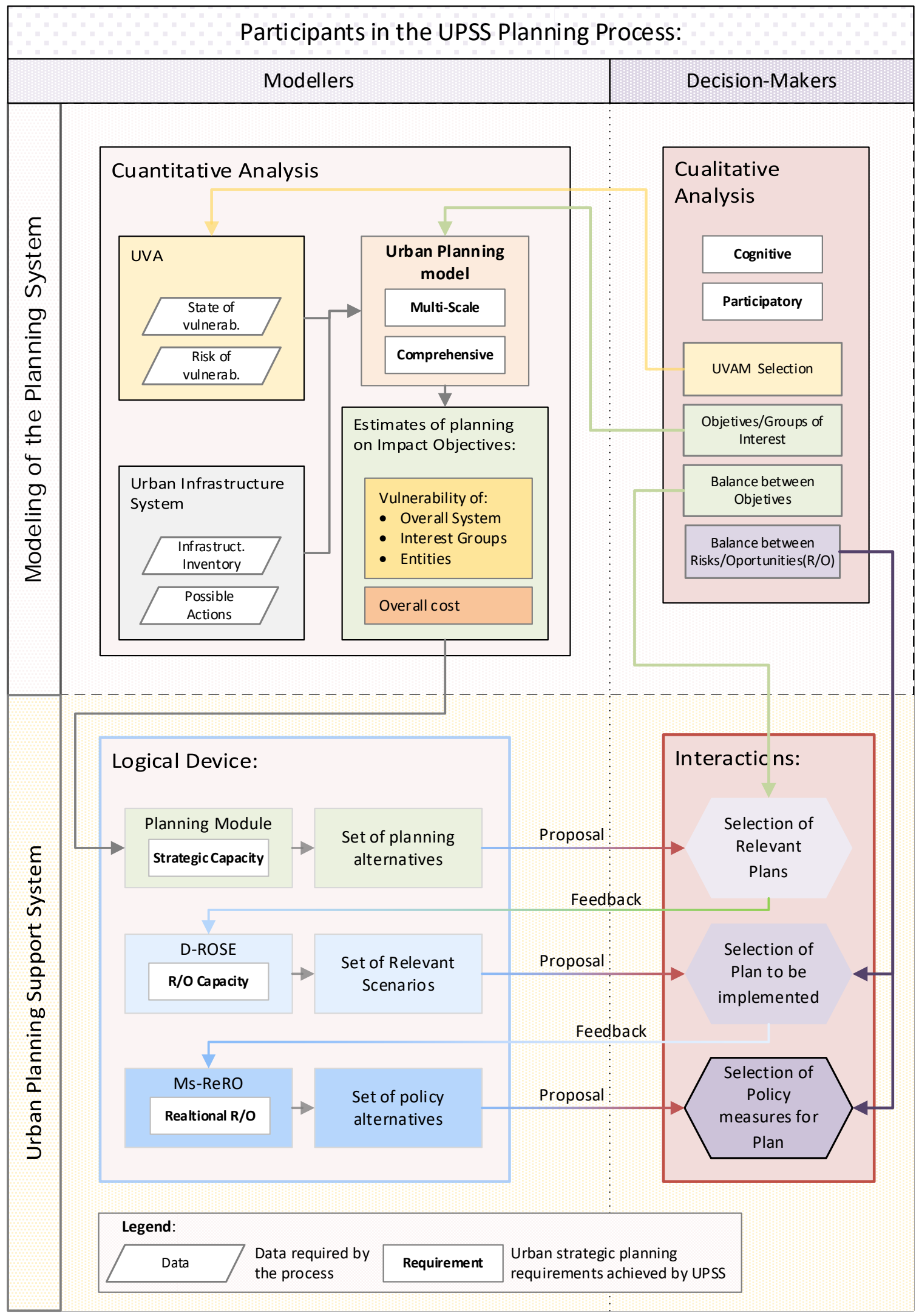

Figure 1 Overall workflow and USP requirements achieved by the urban planning support system

\subsection{General Workflow}


The idea is to elicit general guidelines by following a three-step process. In the first step, once the process set-up has been performed (Fig. 2, I-0), a set of Pareto-optimal models (Fig. 2, S-1) is elicited through the Planning Module (Fig. 2, PM), and analysed (Fig. 2, G-1). In the second step, a set of future SOWs generated by the D-ROSE module (Fig. 2, SM-I) is analysed (Fig. 2, G-2) in order to obtain relevant scenarios (Fig. 2, S-2) and choose a planning alternative (Fig. 2, I-2). As the third step, the MS-ReRO module is run upon the planning alternative selected, to produce policy measures to alleviate eventual problems arising from multi-scale relational uncertainty, and allowing knowledge to be generated (Fig. 2, G-3) to inform the selection (Fig. 2, I-3) of the proper policy measures to accompany the infrastructure plan previously chosen.

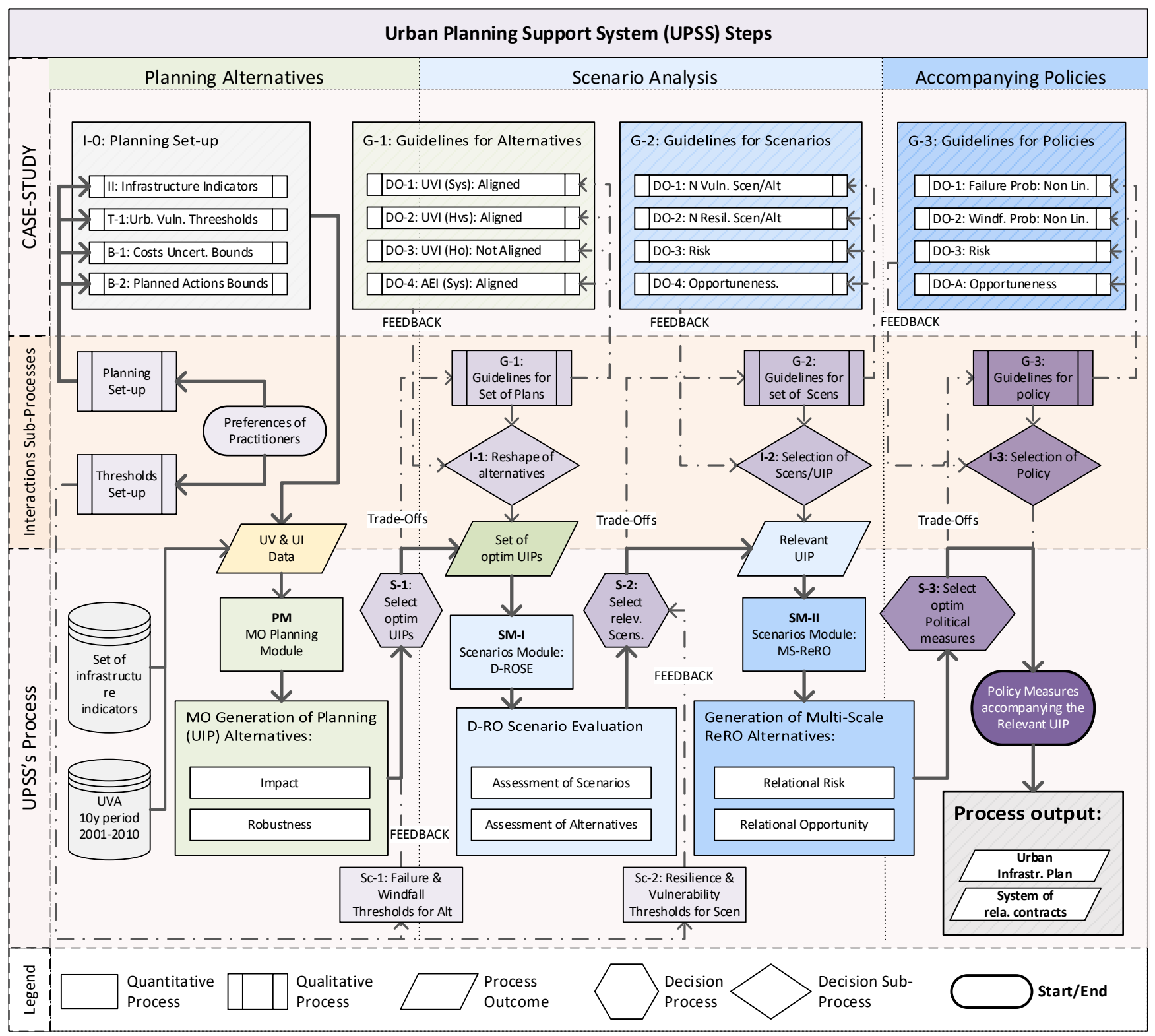

Figure 5.2 Detailed workflow of the planning system and case study

\subsection{Planning module: Generation of Planning (Figure 2, PM)}

The generation of planning alternatives was addressed via formulation of a MOO model 
(Salas \& Yepes, 2018b), in which the decision criteria were implemented as the objectives that the optimization model sought to achieve (Kasprzyk et al., 2013). The framework presented improves the effectiveness of other planning methods also providing sets of possible solutions (APST), by proposing only Pareto-optimal solutions, thus preventing the adoption of less effective, non-relevant alternatives. This feature allows trade-offs to be made between objectives, which can be used as guidelines for the selection of relevant and always optimal planning alternatives, giving the decisional system the strategic capacity (Fig. 1) demanded by current strategic planning that other methods lack (Table 1).

\subsubsection{Definition of impact objectives}

By means of the impact objectives, the effects of solutions (Fig. 2) on the system's urban vulnerability are described and encoded as criteria for selecting alternatives.

\section{Urban vulnerability impact}

Having selected in the process set-up (Fig. 2, I-0) an urban vulnerability assessment (UVA) model, its results were employed to build up statistical models that relate the evolution of infrastructures with the evolution of urban vulnerability. Due to the complex, multi-scale character of urban vulnerability (Adger, 2006), the correlation between its evolution and that of the infrastructure equipment was studied across all the scales present in the UVA model, and specific step-wise multi-variate linear regression models were fitted for each scale to estimate the impact of infrastructure-related variables (Mejia Dorantes et al., 2011). In our case, UV evolutions of each entity were treated as the responses observed, and the evolutions of each type of infrastructure considered were regarded as predictors, enabling the model to assess the impact of changes of the infrastructure equipment on the evolution of UV.

From infrastructure actions to impact changes:

Changes in the infrastructure indicators need actions, implemented though infrastructure planning, to be operated. If there were, for example, a need to change a road's state from poor to good, it would need concrete actions, comprised within the roads rehabilitation category, such as pavement milling and structural resurfacing (Yepes et al., 2016). Following this logic, a device was built relating actions with the explanatory variables accepted by the predictive model (Table 4). By means of this, the model was allowed to transpose infrastructure planning into positive impacts on urban vulnerability, which thus became available as an objective for the generation of planning alternatives.

Infrastructure/Explanatory Vars:

Description
Actions Vars:

Id Unit


Actions Vars:

\begin{tabular}{|c|c|c|c|c|c|c|c|}
\hline Description & Id & Unit & Type & Treatment & SLI & Treat/period & Period \\
\hline \multicolumn{8}{|l|}{ Roads: } \\
\hline Road State Good & 1 & $\mathrm{~m} 2$ & Preservation & 1.02 & 3 & 4 & 4 \\
\hline Road State Poor & 2 & $\mathrm{~m} 2$ & Rehabilitation & 66.74 & 25 & 1 & 67 \\
\hline Road State Execution & 3 & $\mathrm{~m} 2$ & Construction & & & & \\
\hline Road State Fair & 4 & $\mathrm{~m} 2$ & Maintenance & 23.24 & 10 & 1 & 23 \\
\hline Roads State Total & 26 & $\mathrm{~m} 2$ & Build & 496 & 25 & 1 & 496 \\
\hline Road Ownship Province & 5 & $\mathrm{~m} 2$ & Transference & & & & \\
\hline Road Ownship Region & 6 & $\mathrm{~m} 2$ & Transference & & & & \\
\hline Road Ownship Central & 7 & $\mathrm{~m} 2$ & Transference & & & & \\
\hline Road Ownship Other & 8 & $\mathrm{~m} 2$ & Transference & & & & \\
\hline Roads Ownship Total & 27 & $\mathrm{~m} 2$ & & & & & \\
\hline
\end{tabular}

\section{Point Infrastructures:}

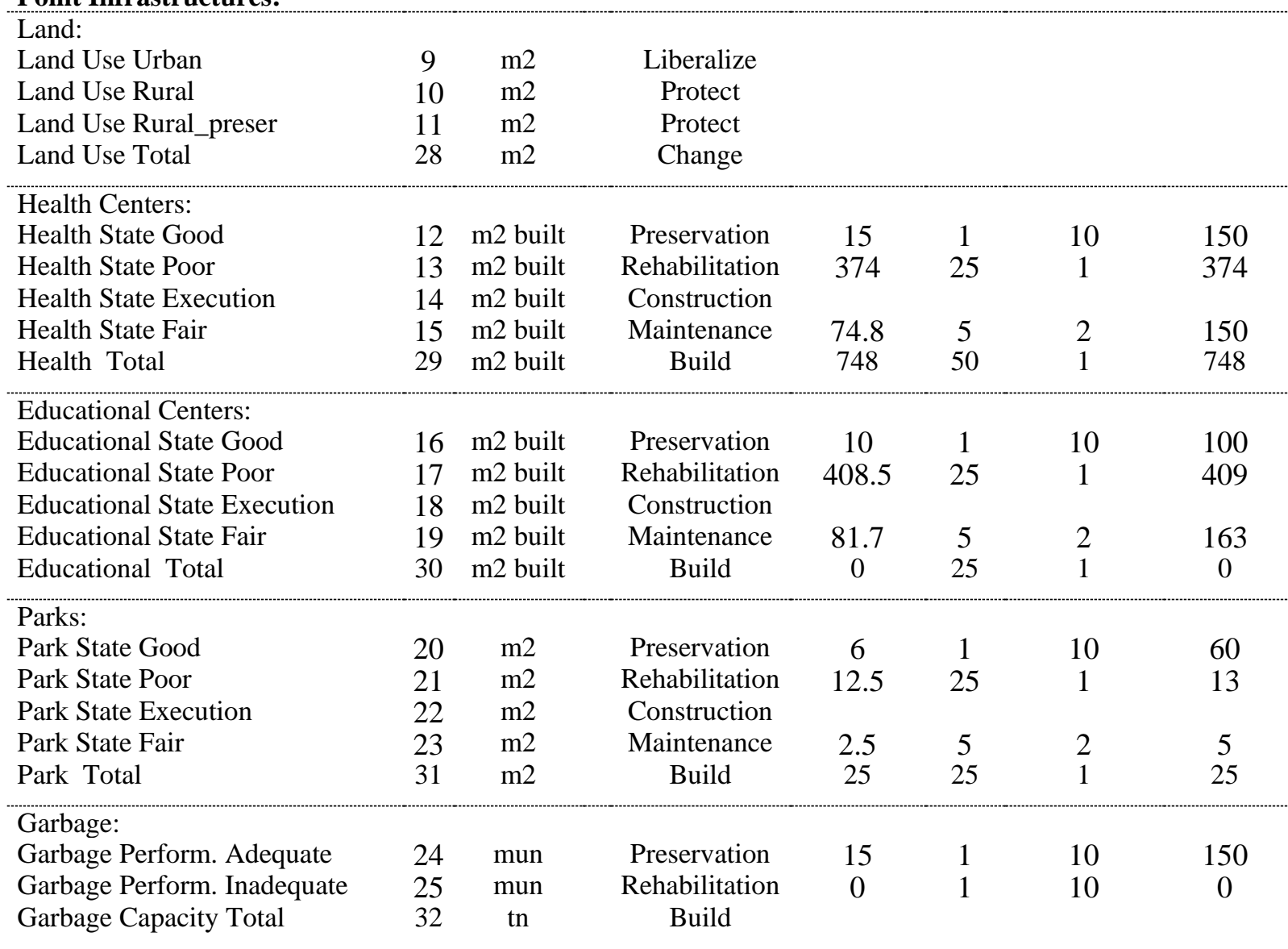

(*) Service Life Increase

$(* *)$ Number of treatments required along the period being considered

Table 5.4 Infrastructure variables and planning actions

Economic impact:

Along with the impact on the evolution of UV, actions were evaluated in terms of their economic impact by means of assigning costs to actions, and two types of impacts were thus obtained for each entity, namely the urban vulnerability impact (UVI), and the actions economic impact (AEI), whose overall formulation is as follows: 


$$
\begin{aligned}
U V I_{\text {Sys }} & =\sum_{i, j} U V I\left(\operatorname{Plan}_{j}, \operatorname{Mod}_{i}\right) \\
A E I_{S y s} & =\sum_{i, j, k} \operatorname{Action~}_{(i, j, k)} \times \operatorname{ICost}_{(i, j, k)} \times \operatorname{IcostAsymm}_{(i, j)}
\end{aligned}
$$

where $U V I_{\text {Sys }}$ and $A E I_{\text {sys }}$ are respectively the $\mathrm{UV}$ and the overall economic impacts of the Sys system, $i$ is each of the system's hierarchical scales, $j$ is each of the entities in $i$ scale, $k$ is each of the actions planned for the $j$ entity, UVI is the evaluation of the Plan set of actions planned for each $j$ entity under the $M o d$ regression model assigned to each $i$ scale, Action and ICost are, respectively, the quantification of actions and unitary costs

\begin{tabular}{|c|c|c|c|c|c|c|}
\hline \multirow{2}{*}{\multicolumn{2}{|c|}{ Region }} & \multirow{3}{*}{$\begin{array}{l}\text { Normalyze } \\
\text { d } \\
\text { Asymmetry } \\
\text { Index }\left(^{*}\right)\end{array}$} & \multicolumn{4}{|c|}{ Accompanying Policy } \\
\hline & & & \multicolumn{2}{|c|}{$\begin{array}{l}\text { Config of } \\
\text { IGRCs }(* *)\end{array}$} & \multicolumn{2}{|c|}{$\begin{array}{c}\text { ReRO Inter-Scale } \\
\text { Assessment }\end{array}$} \\
\hline ID & Name & & Rig & Dutie & Risk & Opportunity \\
\hline 0 & Nacional & 1 & & & $6,24 \mathrm{E}+06$ & $5,17 \mathrm{E}+06$ \\
\hline 1 & Andalucía & 0.895 & 12 & & 0 & $1,14 \mathrm{E}+07$ \\
\hline 2 & Aragón & 1.1826 & 12 & & $5,16 \mathrm{E}+05$ & 0 \\
\hline 3 & Asturias & 1.002 & 16 & & $1,45 E+03$ & $0,00 \mathrm{E}+00$ \\
\hline 4 & Balears & 0.9008 & 16 & & 0 & $1,69 \mathrm{E}+06$ \\
\hline 5 & Canarias & 0.9295 & 15 & & 0 & 0 \\
\hline 6 & Cantabria & 1.0407 & 15 & & $4,48 \mathrm{E}+05$ & 0 \\
\hline 7 & Castilla y León & 1.0467 & 15 & & $3,71 E+06$ & 0 \\
\hline 8 & Castilla - La & 1.0286 & 13 & & $4,91 \mathrm{E}+07$ & 0 \\
\hline 9 & Cataluña & 1.1041 & 16 & 3 & $1,07 \mathrm{E}+05$ & 0 \\
\hline 10 & Comunitat Valenciana & 0.98 & 15 & & $3,19 E+05$ & $1,36 \mathrm{E}+05$ \\
\hline 11 & Extremadura & 0.9325 & 14 & & 0 & 0 \\
\hline 12 & Galicia & 0.9381 & 15 & & 0 & $1,25 E+06$ \\
\hline 13 & Madrid & 1.0072 & 15 & & 8,29E+03 & 4,93E-01 \\
\hline 14 & Murcia & 0.9463 & 15 & & $5,40 \mathrm{E}+00$ & $1,30 \mathrm{E}+04$ \\
\hline 15 & Navarra & 1.214 & 14 & & $2,16 \mathrm{E}+05$ & 0 \\
\hline 16 & País Vasco & 1.1138 & 15 & & $8,83 E+06$ & 0 \\
\hline 17 & Rioja, La & 1.1526 & 14 & & $3,34 \mathrm{E}+03$ & 0 \\
\hline 18 & Ceuta & 0.8947 & 15 & & 0 & 0 \\
\hline 19 & Melilla & 0.8537 & 15 & & 0 & 170881,6407 \\
\hline 20 & Provinces $(* * *)$ & By region & 10 & 0,025 & $3,91 \mathrm{E}+07$ & $3,73 E+05$ \\
\hline 21 & Cities $(* * *)$ & By & 12 & 0,015 & $3,69 \mathrm{E}+04$ & $1,93 E+04$ \\
\hline$(*)$ & Extracted from costs of & ousings, Inde & regio & (Spani & & \\
\hline$(* *)$ & Inter-Governmental Re & tional Contrac & & & & \\
\hline$(* * *$ & Mean of values & & & & & \\
\hline
\end{tabular}
of each $k$ action, and IcostAsymm is the normalized asymmetry index (Table 5).

Table 5 Asymmetry index and process results by regions

\subsubsection{Definition of groups of interest}

When coping with urban vulnerability, specific attention should be paid to the most vulnerable entities (Adger, 2006). In consequence, a metric was added in order to enable DMs to account for the relative differences in the impact of each planning alternative on 
the group of the most vulnerable, i.e., to take equity into account (Sierra et al., 2018a). As a result, a high vulnerability state threshold (HVST) was generated to select, for each scale, the group of the highest vulnerability state ( $H v s$ ) entities as those beyond that limit. This allowed the elicitation of the $U V I_{H v s}$ and $A E I_{H v S}$ metrics, obtained in an analogous way to the $U V I_{S y s}$ and $A E I_{S y s}$ but accounting only for those entities included in the $\mathrm{Hv}$ group:

$$
\begin{aligned}
& H v s=\left(H v s_{1}, \ldots, H v s_{i}\right): H v s_{i}= \\
& \left(e^{n n t_{i 1}}, \text { ent }_{i 2}, \ldots, e t_{i j}\right) \forall e n t_{i j} \mid \text { StateRank }_{i}\left(\text { ent }_{i j}\right)>H V S T_{i}
\end{aligned}
$$

where $H v s_{i}$ is the group of the $j$ entities at $i$ scale whose position in the StateRank $k_{i}$ is above the $H V S T_{i}$ threshold.

In a similar vein, it would also be of interest for decision-makers to know the impacts on entities presenting the best opportunities to improve their state of vulnerability (SV) in the future, understood as the situation in which entities present a low state of vulnerability and a high chance of becoming less vulnerable (Salas \& Yepes, 2018b). Conversely to the criterion required to become a member of the Hvs group, for being a member of the low vulnerability state group ( $L v s$ ), the condition was to have a StateRank below the low vulnerability state threshold (LVST). In addition to this requirement, members of the high opportunity group ( $\mathrm{Ho}$ ) were also required to have a risk of vulnerability below the low vulnerability risk threshold ( $L R T)$, and therefore the rule to become a member of the high opportunity group was formulated as follows:

$$
\begin{aligned}
& H o=\left(H o_{1}, \ldots, H o_{i}\right): H o_{i}=\left(\text { ent }_{i 1}, \ldots, \text { ent }_{i j}\right) \forall \text { ent }_{i j} \mid \text { StateRank }_{i}\left(\text { ent }_{i j}\right)< \\
& \operatorname{LST}_{i} \wedge \operatorname{RiskRank}_{i}\left(\text { ent }_{i j}\right)<L R T_{i}
\end{aligned}
$$

where $H o_{i}$ is the group of the $j$ entities at $i$ scale whose position in the RiskRank $k_{i}$ is below the $L R T_{i}$ threshold, while its position in the StateRank $k_{i}$ is below the $L S T_{i}$ threshold.

Based on the above, the $U V I_{H v s}, A E I_{H v S}, U V I_{H o}$ and $A E I_{H o}$ metrics were obtained in an analogous way to those for the whole system $\left(U V I_{S y s}\right.$ and $\left.A E I_{S y s}\right)$ but limiting to entities included in the Hvs or in the Ho group. In consequence, the proposed planning framework can effectively represent the consequences of infrastructure plans for specific groups of interests, such as those more vulnerable, promoting stakeholders engagement and improving the participatory capability of the whole method by enabling participants to appreciate the returns that each planning alternative may have for them.

\subsubsection{Definition of robustness objective}


Monte Carlo simulation is recognized as an appropriate method for uncertainty analysis and has been previously used to incorporate uncertainties into optimization models (Liao et al., 2011). Broadly speaking, this method analyses how a model's outcome behaves when the inputs vary from their expected values following a given probability distribution. Once Monte Carlo simulation has been performed, the robustness of the model can be evaluated by assessing, for each $k$ input variable, the relative size of its variance $v$ with respect to its mean $m$, and then aggregating these ratios, obtained for the $n$ variables composing the model, to assess its overall robustness $R_{o b} b_{S y s}$ (Salas \& Yepes, 2018b):

$$
\operatorname{Rob}_{\text {Sys }}=1 /\left(\sum_{k=1}^{n}\left(\frac{v_{k}}{m_{k}}\right)\right)
$$

where models with small variance in comparison with the mean are robust (Hermeling et al., 2013).

Table 5 portrays all the objectives considered in the multi-objective configuration (column B), which can be formulated as:

$$
\begin{aligned}
& \text { minimize } F(x)=\left(f_{1}(x), \ldots, f_{o b j}(x)\right) T \\
& \text { s.t. } x \in \Omega, \forall x \leq \operatorname{Last} P \times\left(1+\mathrm{PA}_{\mathrm{Scope}}\right) \wedge x \geq \max (\text { Last } P \times(1- \\
& \left.\left.\mathrm{PA}_{\mathrm{Scope}}\right), \text { Last } P \times\left(1-\mathrm{PA}_{\mathrm{Lb}}\right)\right),
\end{aligned}
$$

where $\Omega$ is the decision space, LastP is the last plan carried out, $\mathrm{PA}_{\mathrm{Scope}}$ is the range of possible values around LastP, $\mathrm{PA}_{\mathrm{Lb}}$ is the minimum actions to be carried out in the current plan, $x \in \Omega$ is a decision vector and $o b j$ is the objective function according to Table 5. 


\begin{tabular}{lll}
\hline Variables: & & \\
\hline Item & Description & Eq \\
& & u.
\end{tabular}

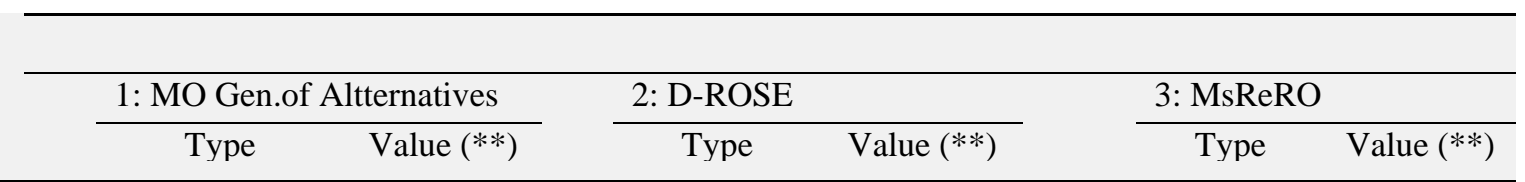

\section{Planning Module:}

Alternative

UIP Urban Infrastructure Plan coping with UV

5.6

Decision

Variahlo

BaseLine

nats

Parameter

Set-up of Alternatives:

PA_Scope Range of Possible Actions (from previous 5.6

PA_Lb Max.percent of unnatended actions from max.

Optimization

0.15

Param

0.25

Objectives (Assessment of Alternatives):

\begin{tabular}{|c|c|c|c|c|c|c|c|}
\hline UVI(Sys) & Impact on Sytem's Urban Vulnerability & 5.1 & Optimization & $-8.60 \mathrm{E}+7$ & BaseLine & $-2.68 \mathrm{E}+03$ & BaseLine \\
\hline UVI(Hvs) & Impact on Highly vulnerable entities' UV & 5.2 & \multirow{7}{*}{$\begin{array}{l}\text { Objective, } \\
\text { Criteria for } \\
\text { selecting a set } \\
\text { of relevant } \\
\text { alternatives } \\
\text { (fig } 5.2, \mathrm{~S}-1 \text {; } \\
\text { vid 1) }\end{array}$} & $-2.27 \mathrm{E}+6$ & Data & $-1.22 \mathrm{E}+08$ & Data \\
\hline UVI(Ho) & Impact on High opp. entities' UV & 5.3 & & $-6.27 \mathrm{E}+7$ & & $-2.56 \mathrm{E}+06$ & \\
\hline AEI(Sys) & System's costs of all infrastructure projects & 5.3 & & all & & $2.04 \mathrm{E}+08$ & \\
\hline AEI(Hvs) & Economic Impact on Highly vulnerable entities & 5.4 & & all & & $2.86 \mathrm{E}+06$ & \\
\hline AEI(Ho) & Economic Impact on High opp. Entities & 5.4 & & all & & $3.15 E+07$ & \\
\hline Rob(Sys) & Sys's Robustness against economic costs' & 5.5 & & all & & 22.2896 & \\
\hline \multicolumn{7}{|c|}{ Set-up of Impact Objectives: } & \\
\hline HVST & High vulnerability state threshold (most & 5.3 & Objectives' & {$[30,30,30]$} & \multirow{6}{*}{$\begin{array}{c}\text { BaseLine } \\
\text { Data }\end{array}$} & & BaseLine \\
\hline LVST & Low vulnerability state threshold (less & 5.4 & set-up & {$[30,30,30]$} & & & Data \\
\hline LRT & Low Risk Threshold (less risk) & 5.4 & parameters [by & {$[30,30,30]$} & & & \\
\hline Icost & Infrastructures costs by activities & 5.2 & BaseLine Data & Table 5.1 & & & \\
\hline ICostAsym & Infrastructure costs Asymmetry Index & 5.2 & & Table 5.3 & & & \\
\hline \multicolumn{7}{|c|}{ Set-up of Construction Costs' uncertainties (Robust. Obj.): } & \\
\hline CC_Lb & Lower bound (\% from baseline) & & MC & 0.2 & Baseline & & Baseline \\
\hline CC_Ub & Upper bound (\% from baseline) & & Simulation ex & 0.15 & Parameter & & Parameter \\
\hline
\end{tabular}




\begin{tabular}{lll}
\hline Variables: & \\
\hline Item & Description & Eq \\
& u.
\end{tabular}

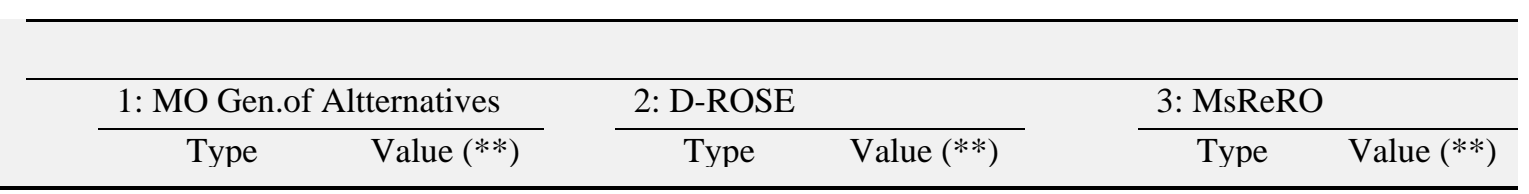

Scenarios Module:

BaseLine Relational Contracts:

$\begin{array}{llcr}\text { Rights } & \text { Rights that are transferred } & 5.7 & \text { Scen } \\ \text { Duties } & \text { Duties that are commited } & & \text { B } 0.3 ; 0.2 ; 0.2 \\ \text { [3;2.5;1.5] }\end{array}$

Scenario Metrics (Assessment of Scenarios/Alternatives):

N(Alt_Vul Number of vulnerable alternatives per scenario

N(Alt_Res Number of resilient alternatives per scenario $\quad 5.23$

ScenR Scenario Risk $\quad 5.19$

ScenO Scenario Opportunity $\quad 5.20$

N(Scen_V Number of relevant vulnerable scenarios $\quad 5.17$

N(Scen_R Number of relevant resilient scenarios $\quad 5.18$

AltR Alternative Risk $\quad 5.24$

AltO Alternative Opportunity $\quad 5.25$

TotFail Total Failure probability $\quad 5.26$

TotWindF Total Windfall probability $\quad 5.27$

ReFail Relational Failure probability $\quad 5.11$

$12.71 \%$

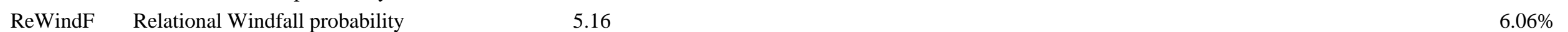

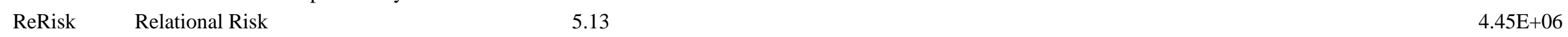

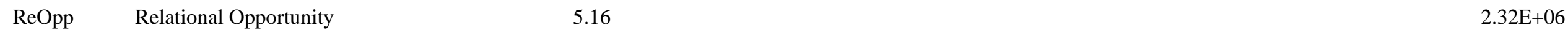

Set up of Scenario Metrics:

TF Threeshold for Failure (\% cost increase from

7

$(+) 0.01$

(+) 0.01 


\begin{tabular}{|c|c|c|c|c|c|c|c|c|c|}
\hline \multicolumn{3}{|l|}{ Variables: } & & & & & & & \\
\hline \multirow[t]{2}{*}{ Item } & \multirow[t]{2}{*}{ Description } & \multirow{2}{*}{$\begin{array}{l}\text { Eq } \\
\text { u. }\end{array}$} & 1: MO Gen & ltternatives & \multicolumn{2}{|l|}{ 2: D-ROSE } & & \multicolumn{2}{|l|}{ 3: MsReRO } \\
\hline & & & Type & Value $(* *)$ & Type & Value $(* *)$ & & Type & Value $(* *)$ \\
\hline TE & $\begin{array}{l}\text { Threeshold for Exploitation (\% cost decrease } \\
\text { from baseline) }\end{array}$ & 7 & & & $\begin{array}{l}\text { U. Metrics } \\
\text { ex ante } \\
\text { param. (fig }\end{array}$ & $(-) 0.01$ & $\begin{array}{c}\text { Scen } \\
\text { ex } \\
\text { ante }\end{array}$ & $(-) 0.01$ & \\
\hline \multicolumn{10}{|c|}{ Set-up of Scenarios' Uncertainties: } \\
\hline Rights_Ub & Upper bound for rights (from Scen baseline & & & & $\mathrm{MC}$ & 0.15 & & Optimizati & 0.15 \\
\hline Rights_Lb & Lower bound for rights (from Scenbaseline & & & & simulation & 0.5 & & on & 0.5 \\
\hline TVul & Threeshold of vulnerability (min required) & 5.21 & & & Scen ex & 5.2 & & & \\
\hline TRes & Threeshold of resilience (min required) & 5.21 & & & post & 1.27 & & & \\
\hline
\end{tabular}

$\left(^{*}\right) \quad$ Scales are regions, provinces and cities

$\left({ }^{* *}\right) \quad$ In bold, values corresponding to the UIP resulting from the decisional framework

Table 5.6 Problem formulation, variables and framework results 
2.3 Scenarios module, discovering scenarios and proposing policy measures (Figure 2, SM-I \& SM-II)

\subsubsection{Co-ordination policy options into a decision-making framework}

With regard to the decision-making process, articulating a contract among the scales coordination policy option into a complex, multi-scale infrastructure system entails the transfer of both attributions and responsibilities from upper to lower hierarchical scales. In other words, this decision-making process follows a top-down sequence, in which the coordination between scales is shaped by a relational contract. However, there is no specific best relational contract to be applied in general. On the contrary, the best solution depends upon the nature of the problem and upon the institutional context in which the contract takes place (OECD, 2007), and it takes form as a particular setting of mutual rights and duties between scales (Frank \& Martínez-Vázquez, 2015). Besides, since the institutional context is in turn dependent on the entity considered within a given scale, a systemic approach for determining an appropriate governmental contract among scales should consider both vertical and horizontal asymmetries among scales and among elements of the same scale respectively (Frank \& Martínez-Vázquez, 2015).

\subsubsection{Multi-Scale Relational Risk and Opportunity (MS-ReRO) assessment of hierarchical multi-scale systems}

\section{Co-ordination policy options: finding the best model}

To represent multi-scale government contracts, two sets of variables representing the rights and duties transferred between parties (Charbit \& Michalun, 2009) were considered. Rights were modelled as the range in which sub-entities can choose actions alternative to the baseline of their upper entity, which means they were treated as variables. Duties, in turn, represented the common objectives agreed in the contract, to the fulfilment of which the parties must be committed (Frank \& Martínez-Vázquez, 2015), and they were therefore a constraint, outside which the contract was considered to fail. As a consequence, for any entity whose performance relies upon that of a set of subentities, a governmental contract between them can be defined as a function of the thresholds of choice allowed (rights), and of the performance demanded from each subentity (duties) to attain the common objectives agreed.

Since, in a multi-scale system, entities depend for their performance on other sub-entities in the lower scale to which rights and duties are transferred, there is a risk of failure for the former, induced by the behaviour of those sub-entities on which it depends (Fig. 2). 
From the perspective of the overall (baseline) performance, governmental contracts are mechanisms for transferring the decision-making capacity (rights) across scales, entailing a certain risk of failure that is propagated across scales as a bottom-up effect (Fig. 2). In such a system, entities may fail due to the behaviour of their sub-entities, where failure is understood as the lack of fulfilment of the entity's duties. Conversely to this risk, the opportunity reflects the probability and the impact of achieving a better performance than expected (windfall) due to the action of the sub-entities, which are assumed to have a better knowledge of the local circumstances that can be translated into, for example, minimizing costs (Frank \& Martínez-Vázquez, 2015).

This implies that finding the best policy alternative for setting up inter-scale contracts needs to balance the pros (opportunities) and cons (risks) entailed by every policy alternative. These are defined by the choice (right) and the performance (duty) thresholds attached to each contract. The Multi-Scale Relational Risks and Opportunities (MSReRO) method proposed in this paper aims to contribute to the above by providing policy alternatives that offer compromise solutions attending to risks and opportunities.

\section{Modelling a system of relational contracts}

As pointed out by Eusgeld et al. (2011), risk assessment of the relational contracts system overall performance should consider the probability of a relational failure induced by the failure of sub-entities across all scales, which can be modelled as a failure tree (Figure 3). Failure $(F)$ is defined as the state $S$ in which the $A E I_{i, j}$ economic evaluation of entity $(i, j)$ (section 2.2.1) is below a given Threshold of Failure $(T F)$. Conversely, Windfall $(W)$ is defined as the state $S$ in which $A E I_{i, j}$ is above a given Threshold of Windfall (TW):

$$
S_{i, j}=\text { Fail } \Leftrightarrow A E I_{i, j}<T F ; S_{i, j}=\text { Windfall } \Leftrightarrow A E I_{i, j}<T W
$$

The probability of this failure being caused by the sub-entities' lack of commitment to a relational contract with $R$ rights (Figure 3) could be assessed, for each entity, as the posterior probability of failure of that entity given the failure of any of its sub-entities deviated $r \in \mathrm{R}$ from the base overall planning:

$$
\begin{aligned}
& P\left(F_{i, j}^{R}\right)=\frac{N\left(F_{i, j}\right)}{N\left(A E I_{i, j, r}\right)} \\
& P\left(F_{i, j} \mid F S_{i, j}^{R}\right)=\frac{N\left(F_{i, j} F s^{R}{ }_{i, j}\right)}{N\left(F_{i, j}\right)}
\end{aligned}
$$

where $P$ is the probability of the failure event, $F^{r}{ }_{i, j}$ refers to failure of the entity $i, j, F s^{r}{ }_{i, j}$ refers to the failure of any of the sub-entities on which the entity depends, and $N$ refers to the number of times that an event was observed. 
Therefore, the probability of a relational failure induced on the entity by the failure of its sub-entities $P\left(F_{i, j} F s^{R}{ }_{i, j}\right)$ was formulated using the law of total probability as:

$$
P\left(F_{i, j} F S_{i, j}^{R}\right)=P\left(F_{i, j} \mid F S^{R}{ }_{i, j}\right) \times \sum_{s=1}^{n S} P\left(F S_{i, j}^{R} F s S^{s R}{ }_{i, j}\right)
$$

where $\left(F S{ }_{i, j} F s S^{S R}{ }_{i, j}\right)$ is the probability of failure of any of the sub-entities "s" to which entity $i, j$ is attached, given the failure, under a sub-contract with rights $s r$, of any of the "ss" sub-sub-entities to which the sub-entities are in turn attached:

$$
P\left(F S_{i, j}^{R} F s S^{S R}{ }_{i, j}\right)=P\left(F S^{R}{ }_{i, j} \mid F s S^{S R}{ }_{i, j}\right) \times \sum_{S S=1}^{n S S} P\left(F S S^{S R}{ }_{i, j}\right)
$$

where $P\left(F S^{R}{ }_{i, j} \mid F s S^{s R}{ }_{i, j}\right)$ is the conditional probability of failure of the $s$ given the failure of any $S S$ of its $n S S$ sub-sub-entities, and $P\left(F S S{ }_{i, j}\right)$ is the probability of this failure.

For the elicitation of probabilities, the method employed a Monte Carlo simulation-based approach, which has been previously used to deal with complex-system failure problems (Nguyen et al., 2015). This technique evaluates the system through a large number of scenarios, stochastically generated following their pdf. Since the aim was to identify the impact on the performance of entities produced by the actions of sub-entities, this latter was modelled by means of a triangular distribution function whose extreme values were the upper and lower bounds defining the rights endowed by the government contract between the entity and sub-entities (Figure 3). Likewise we selected, as the triangular functions' peak values, those of the actions under the baseline plan, which represents the contract duties (contribution to the overall objective) arranged between the parties.

On this basis, the probability of the system's failure due to the rights and duties bestowed upon its sub-entities through relational contracts was calculated following a bottom-up process, which begins with the probabilities of entities in the basic (lowest) scale, and propagates across the scale until the last (system) level (Figure 3). In the lowest scale, the conditional probability and total probability are equal, due to the fact that the entity and the sub-entity are the same.

Given that

$P\left(F S_{1, j}^{R} \mid F s S_{1, j}{ }_{1, j}\right)=P\left(F S_{1, j}^{R}\right)$

And following the criteria employed in UVA assessment (Salas \& Yepes, 2018b), the relational risk was modelled as the product of probability and impact (Dessai and Hulme, 2004):

$\operatorname{ReRisk}\left(F_{S y s}\right)=\prod_{i, j}^{n S c a l e s-1}\left(P\left(F_{i, j} F s^{R}{ }_{i, j}\right) \times \sum_{j}^{n E n t} P\left(F S_{i, j}^{s R} F s S^{s R}{ }_{i, j}\right) \times F I_{i, j}\right)$

where $F I_{i, j}$ is the impact on the performance of the entity " $i, j$ ” produced by the failure 
event $\left(F_{i, j} \mid F s^{R}{ }_{i, j}\right)$ :

$$
F I_{i, j}=A E I^{B L}{ }_{i, j}-\overline{A E I^{F}{ }_{l, j}}
$$

where $A E I^{B L}{ }_{i, j}$ is the baseline performance expected to be attained by the entity $i, j$, and $\overline{A E I^{F}{ }_{l, j}}$ is the mean performance value of the failure events observed for that entity (Lempert et al., 2006).

Taking the values of the best cases, the windfall impact was formulated conversely to that of risk, as

$$
W I_{i, j}=A E I^{B L}{ }_{i, j}-\overline{A E I^{W}{ }_{l, J}}
$$

where $\overline{\overline{A E I^{W}}}$ is is the mean performance value of the windfall events. As in the case of risk, opportunity was calculated in terms of the probabilities of the occurrence of windfalls due to the action of sub-entities:

$$
\begin{array}{r}
\operatorname{ReOpp}\left(W_{s y s}\right)=\prod_{i, j}^{n S \text { cales-1}}\left(P\left(W_{i, j} W s^{R}{ }_{i, j}\right) \times\right. \\
\left.\sum_{j}^{n E n t} P\left(W s^{s R}{ }_{i, j} W s s^{s R}{ }_{i, j}\right) \times W I_{i, j}\right)
\end{array}
$$

where $P\left(W_{i, j} W s^{R}{ }_{i, j}\right)$ is the product of the probability of the sub-entities' windfall and the posterior probability of the entity having windfalls, given the windfall of any of the sub-entities.

The above resulted in a system of relational contracts represented by rights and duties between governmental scales, allowing to determine and balance the risks and opportunities attached to them.

\subsubsection{Dynamic Risk and Opportunity Simultaneous Evaluation (D-ROSE) method}

In relation with the overall problem formulation, these bounds, defining the rights assigned to sub-entities, acted as the exogenous factors (section 1, Scenario Analysis) constituting the policy scenarios affecting the behaviour of the infrastructure plans, which thus had to be assessed. This evaluation, carried out through Monte Carlo simulation, rendered the risks and opportunities that a given infrastructure plan conveyed across the range of scenarios (systems of governmental contracts) available, from where methods such as RDM provide the identification of vulnerable scenarios as those in which the alternatives (infrastructure plan) perform poorly (Kasprzyk et al., 2013). This performance was considered to be poor when it violated the vulnerability threshold, previously set up in accordance with the stakeholders' preferences. In our case, this threshold defines a minimum level of performance required, below which scenarios were regarded as more or less vulnerable. Besides, D-ROSE also seeks more resilient scenarios, 
which are identified as those in which more alternatives performed better than the windfall threshold, also as defined by the stakeholders. Therefore, the scenarios' vulnerability and resilience are defined as follows:

$$
\begin{aligned}
& S V_{\text {Scen }}=N(\text { Alt }) \mid f(\text { Alt })<T F \\
& S R_{\text {Scen }}=N(\text { Alt }) \mid f(\text { Alt })>T W
\end{aligned}
$$

where $S V_{\text {Scen }}$ and $S R_{S c e n}$ are the vulnerability and resilience of the "Scen" scenario, Alt are the alternatives, $f$ is the fitness of each alternative, and $T F$ and $T W$ are the failure and windfall thresholds respectively.

We also assessed the scenarios' risks and opportunities as the product of the probability of being a vulnerable scenario, and the impact of such case:

$$
\text { ScenRisk }_{s c n}=P\left(S V_{s c n}\right) \times I\left(S V_{s c n}\right)
$$

where ScenRisk scn $_{\text {is }}$ is the risk inherent to scenario "scn" provided a probability of occurrence $P\left(S V_{s c n}\right)=\left(S V_{s c n}{ }_{N(A l t)}\right)$, and an impact $I\left(S V_{S c e n}\right)=f_{\text {Scen }}^{b}-\overline{f^{S V}{ }_{S c e n}}$, where $f_{\text {Scen }}^{b}$ is the performance of the baseline alternative, and $\overline{f^{S V}{ }_{\text {Scen }}}$ is the mean performance of those alternatives being vulnerable in this scenario.

Conversely, the opportunity inherent to "Scen" $\left(\right.$ ScenOpp $\left._{\text {scn }}\right)$ was defined as follows:

$$
\text { ScenOpp } p_{\text {Scen }}=P\left(S R_{\text {scn }}\right) \times I\left(S R_{\text {scn }}\right)
$$

where $P\left(\operatorname{ScenRes}_{S c e n}\right)=\left(S R_{\text {scn }} / N(\right.$ Alt $\left.)\right)$ is the probability of occurrence, and an impact $I\left(S R_{s c n}\right)=f^{b}{ }_{\text {Scen }}-\overline{f^{S R}{ }_{\text {Scen }}}$, where $\overline{f^{S R}{ }_{\text {Scen }}}$ is the mean performance of the alternatives being resilient in this scenario.

Based on the above, the decision-makers selected the relevant scenarios $\left(\right.$ Relevant $\left._{\text {Scen }}\right)$ as those with the most interesting levels of vulnerability and resilience:

$$
\text { Relevant }_{\text {Scens }}=\left(\text { Scen }_{1}, \ldots, \text { Scen }_{\text {scn }}\right) \mid S V_{\text {scn }}<T V u l \cap S R_{\text {sen }}>\text { TRes }
$$

where TVul and TRes are respectively the vulnerability and resilience thresholds. DROSE in the only method making use of both vulnerability and resilience thresholds, which are dynamically settled ex post, to select relevant scenarios for its further employment, allowing the DM to profit from the knowledge provided by the initial set of scenarios.

As a subsequent step, D-ROSE identifies those infrastructure plans that perform better against vulnerable scenarios and enables DMs to choose, from among them, the one with the most appropriate trade-off between vulnerability and resilience. We defined the 
alternatives' vulnerability and resilience against scenarios $(A V, A R)$ as the number of scenarios in which they had a vulnerable or resilient performance:

$$
\begin{aligned}
& A V_{\text {alt }}=N\left(\begin{array}{ll}
S V_{\text {scn }} \in \text { Relevant }_{\text {Scens }}
\end{array}\right) \\
& A R_{\text {alt }}=N\left(\begin{array}{ll}
S R_{\text {scn }} \in \text { Relevant }_{\text {Scens }}
\end{array}\right)
\end{aligned}
$$

In a similar vein to the case of the scenarios described above, the risk and opportunities inherent to each alternative under the relevant scenarios were formulated as the product of the probability of occurrence and its impact:

$$
\begin{aligned}
& \text { AltRisk }_{\text {alt }}=P\left(A V_{\text {alt }}\right) \times I\left(A V_{\text {alt }}\right) \\
& \text { AltOpp }_{\text {alt }}=P\left(A R_{\text {alt }}\right) \times I\left(A R_{\text {alt }}\right)
\end{aligned}
$$

\subsubsection{Proposing accompanying policies}

As the final step of the scenarios module, the framework aimed to bridge the gap of proposing policy alternatives that ameliorate vulnerabilities (Kasprzyk et al., 2013) while maximizing opportunities (Frank \& Martínez-Vázquez, 2015). For this purpose, a MOO problem was posed in which the thresholds of choice of each entity were the decision variables, and risks and opportunities were objectives to be respectively minimized and maximized (Table 5).

Further, since the aim is to propose systems of contracts that address most of the uncertainty due to the multi-scale nature of the problem, the method proposed also searches for solutions that minimize the amount of uncertainty not covered by the system of relational contracts (RC). This was articulated by minimizing, on the one hand, the probability of failure (Fig. 3, Obj. 1; Eq. 26) while maximizing, on the other hand, the conditional probability of failure due to the structure of relational contracts (Fig. 3, Obj. 2; Eq. 11) so that there was the minimum probability of realizations not covered by RC (Fig. 3, Unc. F).

$$
\begin{aligned}
& P\left(F_{i, j}\right)=\frac{N\left(\text { AEI }_{i, j}\right)}{N\left(\text { AEI }_{i, j}\right)} \\
& P\left(W_{i, j}\right)=\frac{N\left(\text { AEI }_{i, j}\right)}{N\left(\text { AEI }_{i, j}\right)}
\end{aligned}
$$

This resulted in a set of compromise solutions that enabled us to identify not only the relevant and vulnerable/resilient scenarios, but also the trade-offs required for a proper balance of the pros and cons of contracts so as to select the most appropriate policy measures to accompany the chosen infrastructure plan, as described in section 2.3.2, Coordination policy options: finding the best model. 


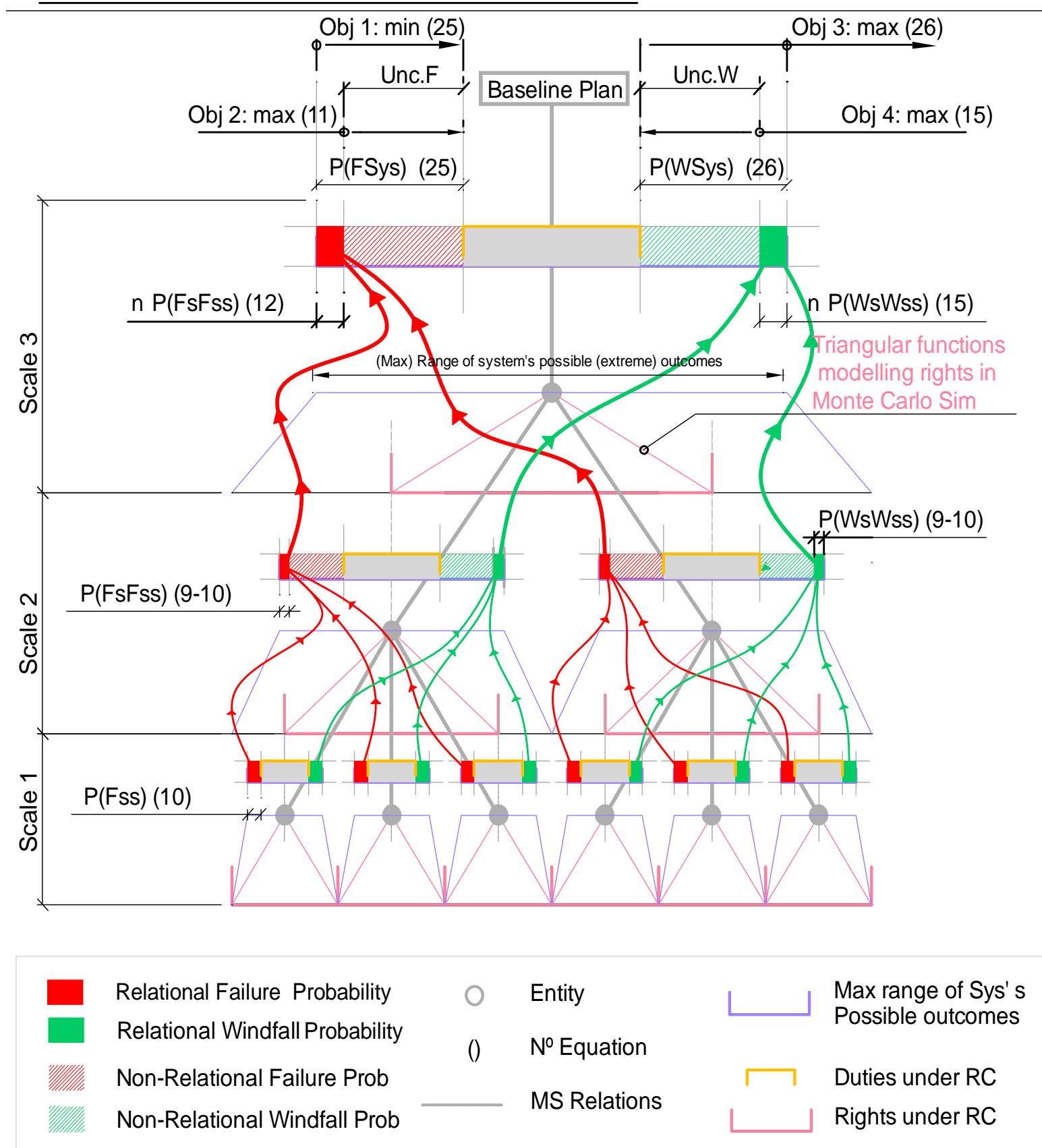

Figure 5.3 Bottom-up propagation through multi-scale hierarchical systems

\section{Case study}

\subsection{Infrastructure planning to address UV in Spain}

In this section, as an exercise to illustrate the usefulness of the framework presented, we considered its application for addressing UV in Spain through infrastructure planning. Following the three-step process mentioned above, the objective is to provide DMs with the guidelines required for the selection of a proper infrastructure plan and its accompanying political measures. 
Spain is a country concerned with UV that has given this concept a key role in the development of strategies involving housing, transportation and infrastructure investments (Infrastructure, transportation and housing plan-PITV 2012-2020, Spanish Ministry of Public Works). For the purpose of assessing UV, this country has developed an Observatory of Urban Vulnerability (OUV), offering data over a set of variables regarding UV. As a consequence, UV has been used in this country as a criterion for the selection of eligible projects for receiving funds from the urban I, urban II and IU programs, which in Spain alone assumed a total investment of $€ 1.037$ million between the years 1994 to 2013. However, previous studies reveal resource-allocation problems (Hurtado, 2012) that derive from the lack of capacity of the assessment approaches employed to provide an overall assessment of all the entities being analysed, across the multiple political-administrative scales in Spain (Hurtado, 2017).

Based on the information available in the OVU, Salas and Yepes (2018b) addressed this issue by proposing a methodology, aligned with the latest trends in urban strategic planning, for the evaluation of urban vulnerability in this country. This method provided an assessment of both the state and the risk of vulnerability for cities with a population of more than 10,000, provinces, and regions. Unlike other methods (Table 1), the planning system presented in this paper can accept a comprehensive assessment of entities in a territory composed of multiple, inter-related organizational scales, and provide overall plans to be implemented by entities of these scales.

Like other OECD members, Spain is a country which has undergone a strong process of decentralisation, transferring major powers from the central government to the regions, including powers regarding infrastructure investment (OECD, 2007). In order to evaluate the degree of performance achieved in the distribution of resources among the different administrations involved in the process of public infrastructure investment, a survey of urban infrastructure (EIEL) was generated in this country to gather data on a wide range of infrastructures from 2000 onwards (EIEL, 2003). This assessment aims to support the proper assignment of public resources in order to minimize inequities among regions, followed by means of better planning of the public infrastructure investment in municipalities. In other words, the EIEL fosters inter-scale vertical co-ordination as well as horizontal equalization, which are among the challenges for attaining a properly decentralized system (Frank \& Martínez-Vázquez, 2015). The data presented in the EIEL comprises a wide range of infrastructures present in municipalities of 50,000 habitants or less in all Spanish regions, with the exception, due to their specific organizational regime, 
of the Basque Country and Navarra.

Since our method required a comparison between data on urban vulnerability and data on urban infrastructure, first we retrieved from the EIEL the data from the same years and scales in which we had assessed UV, i.e. between the years 2000 and 2010, and structured on the city, province and region (autonomous communities) scales.

\subsection{Collection of data and set-up of the process}

All this information was assembled in an SQL database, which in turn was linked to the Matlab ${ }^{\circledR}$ code automating the whole process described in the methodology section, including the planning (2.2) and the scenarios (2.3) modules. Based on the knowledge of the experts involved in this study, a set of 32 variables (Table 4) intended to cover relevant aspects of urban planning for dealing with UV was selected. These variables represented the transport, land use, health, educational, green and recycling infrastructures. Taylor et al. (2006) included attributes concerning the pavement condition and a roads administrative scale for characterizing the vulnerability of strategic road networks, which might have important consequences for socio-economic activities in cities and regions of Australia. Land-use planning and the location of health and educational centres have also been identified as important parameters for strategic decisions regarding regional and urban vulnerability (Menoni and Pergalani, 1994). Voskamp and Van de Ven (2014) pointed to parks and other green infrastructures as suitable means of reducing urban vulnerability to extreme weather events, while Ma and Hipel (2016) related effective and efficient municipal solid waste management with the social dimension of urban vulnerability.

On the other hand, a UVA model was chosen (Fig. 2, I-0) by following the discursive approach described in a previous work (Salas \& Yepes, 2018b), which allowed the process to be initiated. As a subsequent step, the data collected on urban infrastructure were considered as explanatory variables, while those of the UV assessment were taken as the response variable in the regression model. Following the process described in section 2.2.1, a predictive model was then fitted for each governmental scale, comparing the evolution of infrastructure equipment along the period considered with that of urban vulnerability, which enabled an appraisal to be made of the consequences, in terms of the impact on urban vulnerability, of the evolution of the urban infrastructures contained in each entity. In this way, the objective of the UV impact became operative, while for the economic impact, costs were assigned to the infrastructure alternatives (Table 4). 
Regarding the robustness objective, we followed the process described in the methodology section, producing 100 random outcomes for each candidate via the Monte Carlo simulation method. The program was coded in Matlab ${ }^{\circledR}$ with an INTEL ${ }^{\circledR}$ CoreTM i7-4712 CPU processor at $2.3 \mathrm{GHz}$. Starting from an initial random population of 500 individuals, 500 iterations were set as the maximum number of generations to be obtained. Crossover and mutation probabilities were set to 0.6 and 0.5 , respectively.

\subsection{Running the process}

From the planning module, we obtained a set of Pareto-optimal urban infrastructure plans satisfying the abovementioned objectives, which we analysed in order to obtain the guidelines required for informed decision-making. As expected, these solutions showed the trade-offs between the criteria used for the assessment, enabling DMs to select a set of relevant planning alternatives for further assessment (I-1). In a subsequent step, this set of solutions was used to generate, through the scenarios evaluation method described in section 2.3.3, the space of plausible scenarios attached to the decision space (Figure 2, SM-I). This method allowed us to quantify, based on the failure and windfall thresholds (section 2.3.3, Figure 2, Sc-1), both scenarios’ vulnerability and resilience, and determine, according to the vulnerability and resilience thresholds (section 2.3.3, Figure 2, Sc-2), a set of relevant SOWs. This enabled the analyst to check the behaviour of solutions across the set of relevant SOWs in terms of their performance under such assumptions, and to select a desired investment planning according to the knowledge derived from scenario analysis (I-2).

With this knowledge, an infrastructure model was selected (I-2) for further analysis through the MS-ReRO module (Figure 2, SM-II). This resulted in a set of compromise solutions, each of them corresponding to a given set of rights and duties embodied by the inter-scales relational contracts, i.e., with each of the political-administrative scenarios considered in our problem (section 2.3.4). In a subsequent step, a desired system of accompanying policy measures was selected (I-3), enabling the improvement of UV in the cities, provinces and regions analysed through a proper realization of infrastructure planning.

\section{4. $\quad$ Results}

\subsection{Step 1, Guidelines from Planning alternatives (I-1)}

The abovementioned process was used to yield the results needed for the interactions required by the method. In the first stage, i.e. the generation of planning alternatives, a set of Pareto-optimal solutions was obtained. The interpretation of these results provided 
guidelines regarding the trade-offs between the different objectives considered. This enabled us to draw conclusions on the behaviour of the models in terms of their economic and vulnerability impacts on the different interest groups selected, as well as on their robustness to uncertainties regarding economic costs (Table 5). With the knowledge thus acquired, DMs were in a better position to set bounds and to reshape, according to their requirements, the set of initial solutions to obtain a set of relevant UIPs (Fig. 2) for further analysis in the Scenarios module.

Video 1 portrays the trade-off between the UVI(Sys), UVI(Hvs), UVI(Ho) and AEI(Sys) objectives. 


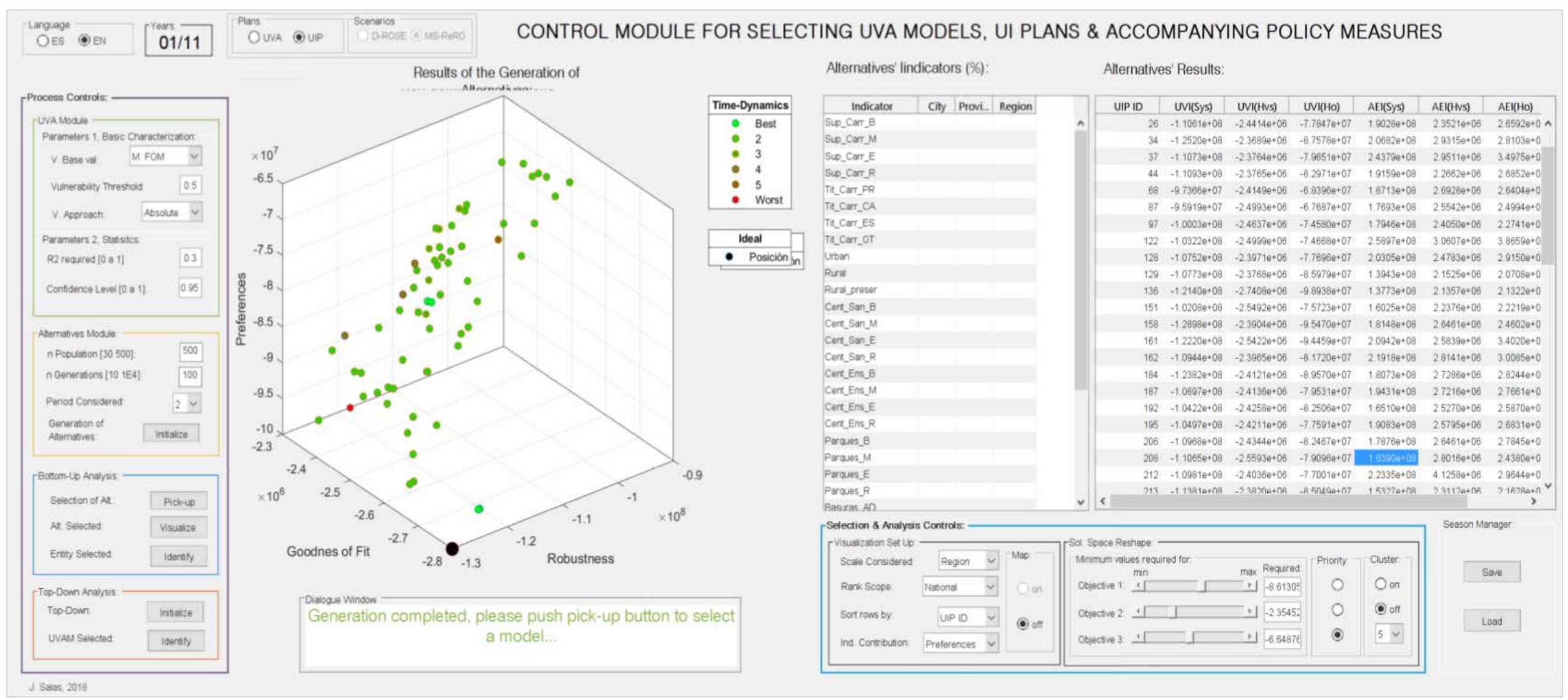

Video 5.1 Selection of relevant UIP 
In addition, we implemented a semi-automated alternative to enhance the extraction of guidelines. The solutions gathered were clustered according to their performance and the AEI(Sys) objective. As a result, the following guidelines were elicited after step 1 (Fig. 2, I-1):

- Most of the solutions that perform well in terms of (lower) overall vulnerability impact are also good in terms of their impact on the opportunity group, suggesting that these two aspects are directly linked.

- Solutions with low (best) economic costs, marked in red, are prone to have higher impacts on the most vulnerable group of entities and vice versa: expensive solutions are worst for this group. On the other hand, it is possible to identify planning alternatives that are good for the overall and high vulnerability impacts in areas with relatively lower costs.

- The impact on entities of the most vulnerable group UVI(Hvs), on the other hand, does not follow UVI(Sys) or UVI(Ho). However, it appears to also have a direct relation with economic costs (green alternatives close to, and red far from, the best UVI(Hvs)), showing that these two objectives are aligned.

\subsection{Step 2, Guidelines for risk and opportunity balance from D-ROSE (I-2)}

After defining the relevant set of UIPs, and prior to running the Scenarios Module, we selected the optimistic and pessimistic thresholds needed to consider whether alternatives had rendered windfalls or failed under each of the scenarios formulated (Fig. 2, Sc-1). On this basis, the different SWO realizations generated by the D-ROSE module were classified as failure, normal or windfall outcomes of the planning being analysed, allowing us to determine the number of vulnerable and resilient scenarios and alternatives, as well as the risks and opportunities associated with them.

The analysis of the results for the second step (Video 2) allows us, as in the previous case, to extract the guidelines for identifying a set of relevant scenarios. In this case, we selected scenarios presenting high levels of vulnerability (Table 5, TVul= 5.2), which we used, in turn, to determine which alternatives behave better under the set of relevant scenarios. For the selection of the set of relevant scenarios, the DMs dynamically set up the resilience and vulnerability thresholds (Fig. 2, Sc-2). 


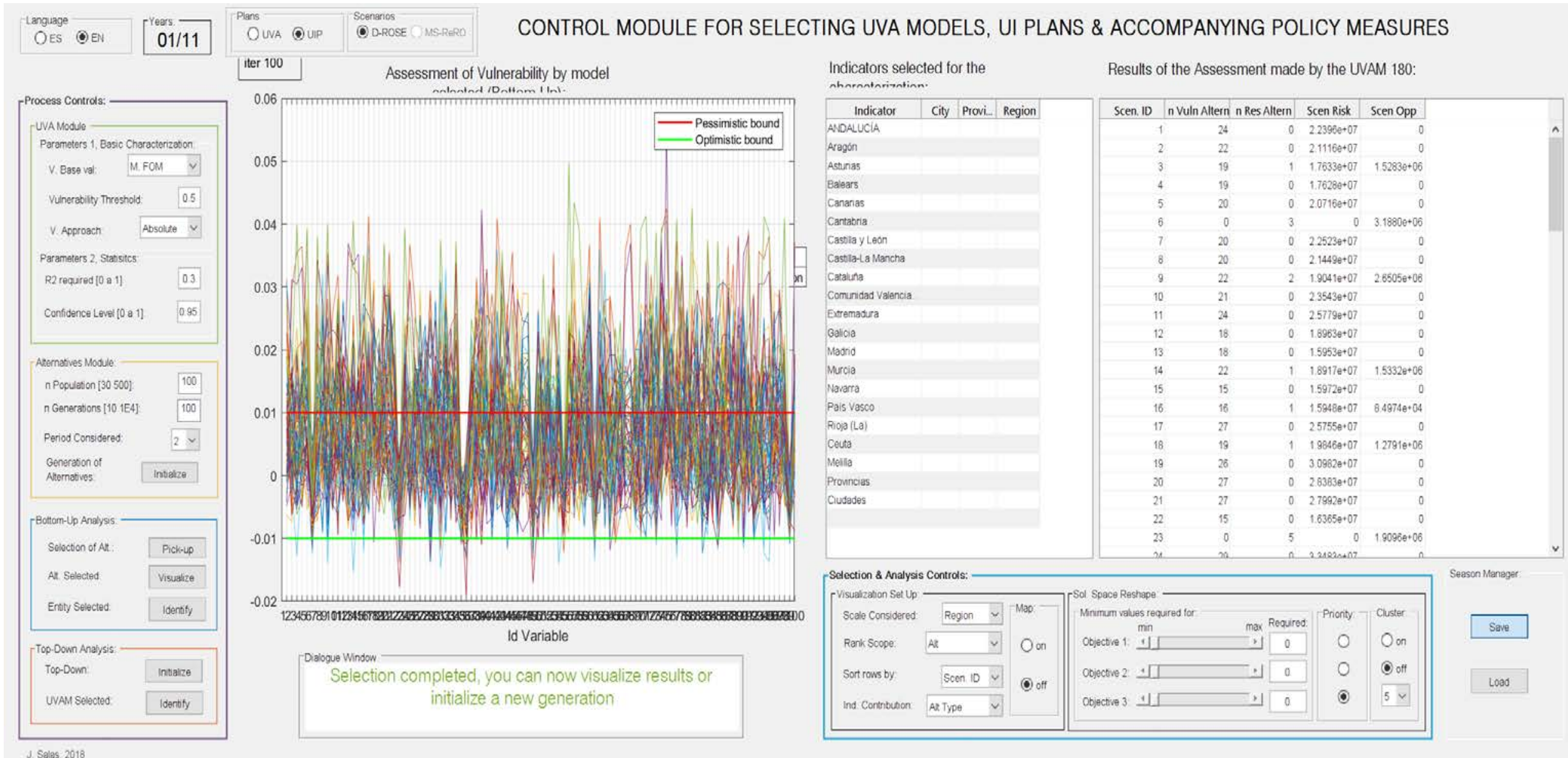

Video 5.2 Selection of relevant scenarios and planning alternatives via D-ROSE 
On this basis, the following guidelines can be drawn up for the set of relevant scenarios and the selection of a desired planning alternative (Fig. 2, I-2):

- $\quad$ D-ROSE identified 7 relevant alternatives that are resilient in at least 2 scenarios. Of these alternatives, ID 56 is the best (cheapest) solution for the overall cost objective, but had a poor balance of risks and opportunities and a high number (11) of relevant scenarios beyond the pessimistic bound. ID 56, as well,. presented the best balance between risks and opportunities, while at the same time performing worst in the overall cost objective (is the most expensive alternative).

- $\quad$ Along with Alt ID 56, Alt 40 had the least number (7) of relevant scenarios beyond the pessimistic bound. In addition to this, Alt 40 had 3 relevant and total scenarios beyond the optimistic bound, while ID 56 had just one, and maintained an acceptable mediumto-good performance in the overall cost objective, leading us to select this as the desired planning alternative.

\subsection{Step 3, Guidelines for risk and opportunity balance from the MS ReRO (I-3)}

The abovementioned guidelines motivated the selection of Alt-ID 40 for subsequent analysis in the MS-ReRO module, which offered policy measures in the form of relational contracts between inter-governmental scales, and evaluated them in terms of the risks and opportunities (Table 5) associated with each of these policy scenarios.

Video 3 presents the selected alternative evaluated under the risk and opportunity objectives, from where the trade-offs among objectives can be inferred. 


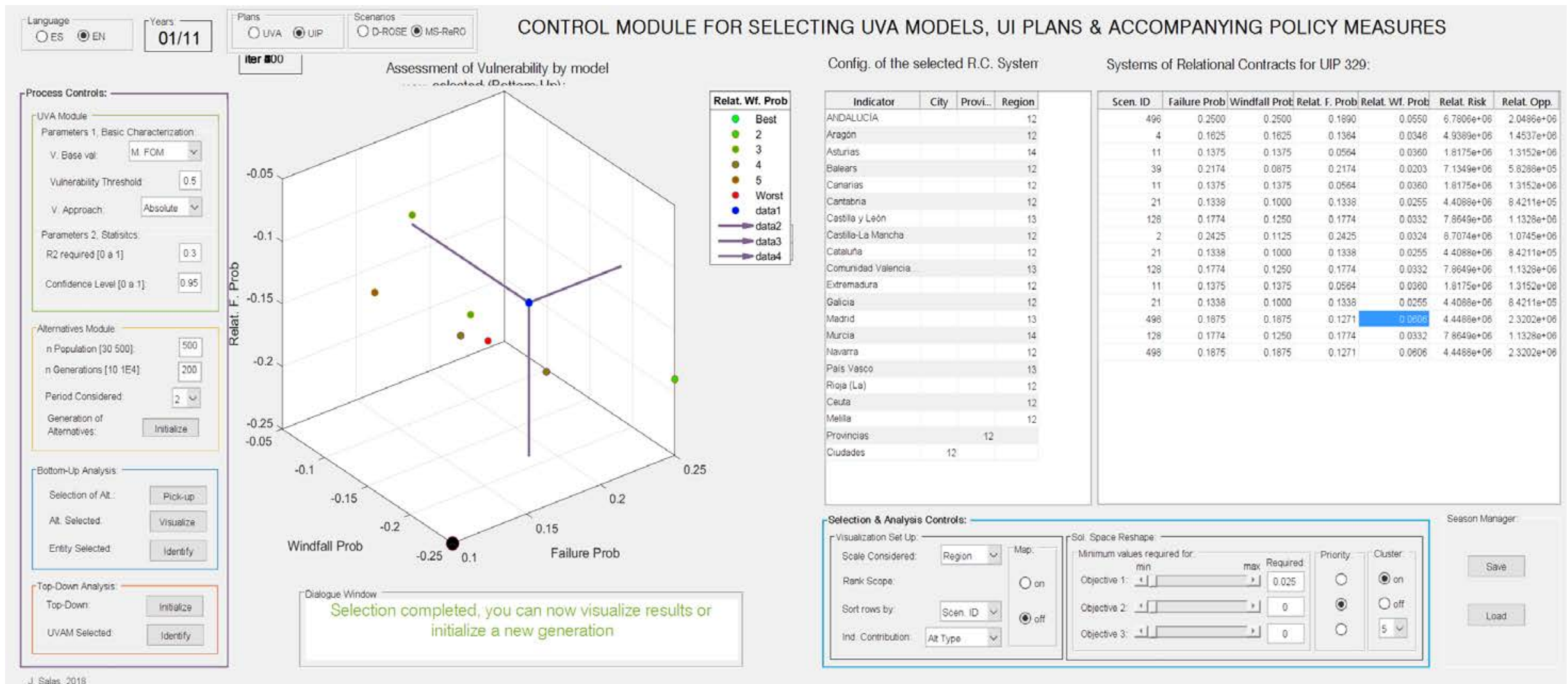

Video 5.3 Selection of accompanying policy alternatives from clustered group 
As in the case of the planning module, the results were filtered following the DM preferences from the MS-ReRO Scenario module, and then clustered into 9 partitions, according to the opportunity objective. The following guidelines were inferred from this step:

- The optimization process yielded several solutions in which the total failure probability was covered by the relational failure probability risk.

- $\quad$ The relationship between failures and windfalls presents high nonlinearities. Indeed, the best solution from the relational windfalls point of view (video 3, green legend) shows a relational failure probability close to that of the alternatives with the least relational windfall probability (video 3, red legend). However, a faint inverse relationship can be observed.

- $\quad$ There are compromise solutions yielding results close to the best regarding both opportunities and risks.

The insights above enabled us to identify alternatives that present a good balance between risks and opportunities. Although Scen-ID 11 presented the best combination of high opportunity and low risk $(\mathrm{ReOpp} / \mathrm{ReRisk}=0.724)$, we dismissed this alternative because it had a high proportion of failure risk not covered by the relational risk (TotFailReFail=8.11\%), which can lead to failures out of the scope of the relational system. We therefore chose the Scen-ID 498 (ReOpp/ReRisk=0.522; TotFail-ReFail=6.04\%) as the most appropriate set of policy measures to accompany the urban infrastructure plan previously selected. This alternative embodied the rights to be transferred, through relational contracts, from the central government to each of the 17 regions and 2 autonomous cities of Spain, as well as those from regions to provinces and from provinces to cities in general (Table 6).

\section{Discussion}

Bottom-up can be generalized into four steps: generating decision alternatives, sampling SOWs, specifying scenarios criteria and evaluating the alternatives in terms of their relations with the scenarios that meet these requirements (Table 4). Info-Gap identifies alternatives that perform well, i.e. satisfying the scenarios criteria, among all the plausible scenarios, from which the alternatives' robustness and opportunities are derived, enabling the DM to balance potential windfall against consistent robustness. Robust Decision Making (RDM) (Lempert et al., 2006), on the contrary, is a PSS focused on vulnerabilities (scenarios where more alternatives perform worst), in which solutions are deemed to be robust when they do not perform worst and minimize the deviation between their 
performance in the worst-case and base-line scenarios. Through the analysis of the tradeoffs between scenarios' characteristics and vulnerabilities, RDM also provides valuable insights to inform the adaptive management of complex environmental systems undergoing change (Kasprzyk et al., 2013).

Like RDM, the Dynamic Adaptive Policy Pathways (DAPP) approach (Haasnoot et al., 2013) is based on worst-case study, and identifies the sequence of policy actions that enables the preferred alternative to go on being valid over time. In other words, DAPP addresses time-dependent uncertainties arising from the dynamic nature of the planning problem being analysed, by evaluating alternative paths for when the current route, at a given moment, will cease to be adequate. This means that DAPP is intended to provide sets of policy actions for a discrete and relatively small set of alternatives, instead of providing robustness assessment for a large set of alternatives across a wide range of scenarios, as in RDM or Info-Gap (Ray \& Brown, 2015).

Like DAPP, Decision Scaling provides a discrete choice framework to assess prespecified design alternatives or to perform vulnerability analysis of existing systems (Ray \& Brown, 2015). As in the case of RDM, Decision Scaling focuses on vulnerabilities, i.e., it identifies scenarios leading to a system's failure, and identifies thresholds that are likely to trigger those vulnerabilities. In contrast with other bottom-up methods, Decision Scaling relies on a subjective estimation of the SOW probabilities obtained through expert evaluation (Hadka et al., 2015).

By identifying failure or windfall events, the abovementioned methods provide risk or opportunity assessment, enabling DMs to learn from the trade-offs between each of them and the general results (Table 3). However, none of the planning systems revised provides planners with an actual risk or opportunity assessment of the planning alternatives. IPSS evaluates alternatives for a set of climate change scenarios, but do not determine risks, nor compares the behaviour of planning alternatives between them to find out which of them offers better prospects given a range of possible future states of the world. The proposed method, in contrast, provides planners with both a risk and opportunity assessment, enabling them to identify solutions that remain valid for a larger portion of uncertainty.

This enriches the elicitation of knowledge from trade-offs which, in the case of D-ROSE, is improved by the ex post, dynamic selection of criteria for the delimitation of relevant scenarios. In contrast, both RDM and Info-Gap employ an ex-ante definition of thresholds 
for delineating sets of relevant scenarios, which does not contribute to a better understanding of the relations between thresholds and scenarios. D-ROSE, in addition, allows this trade-off to be extended to the case of alternatives, allowing us to determine trade-offs among thresholds and vulnerable/resilient alternatives. All this together allows a minute examination and balance of the pros (opportunities) and cons (risks) of the alternatives for a very specific set of scenarios, while keeping in mind a general overview.

The presented method, however, does not claim to automatically provide guidelines for the selection of alternatives, which depends on the specific wishes and ambitions of the decision-makers. Instead, it offers guidance to decision-makers for the essential task of analysing the behaviour of the alternatives with regard to the modelled uncertainties, to enable them to draw their own conclusions and decide accordingly.

Table 7 illustrates the efficacy of the method proposed by comparing the closeness between the selected planning alternative and the ideal alternative, with that of the other optimal alternatives generated to the ideal. We can see how this ideal, defined as the best value of each objective, changes when considering all or only the relevant alternatives, indicating the effect of the decision-makers' preferences on the balance of objectives and therefore on the outcome of the selection process. As a consequence, the distance of the selected alternative from the ideal varies from one set to another, as does the ratio between alternatives farther from the one selected, and alternatives closer to the ideal. The reason why this ratio decreases when moving from considering all to only considering relevant alternatives, is because in the second group we have eliminated non-attractive solutions, thus reducing the number of farther solutions.

\begin{tabular}{|c|c|c|c|c|}
\hline \multicolumn{3}{|l|}{ Objectives } & \multirow{2}{*}{\multicolumn{2}{|c|}{$\begin{array}{l}\text { Distance to Ideal of the } \\
\text { Selected alternative }\end{array}$}} \\
\hline \multirow{2}{*}{$\begin{array}{l}\text { Item (Table } \\
5.6)\end{array}$} & \multicolumn{2}{|c|}{ Ideal values } & & \\
\hline & All & Relevant & All & Relevant \\
\hline \multicolumn{5}{|c|}{ Planning Module: } \\
\hline UVI(Sys) & $-1.47 \mathrm{E}+08$ & $1.29 \mathrm{E}+08$ & $24 \%$ & $20 \%$ \\
\hline UVI(Hvs) & $-2.81 \mathrm{E}+06$ & $2.74 \mathrm{E}+06$ & $14 \%$ & $47 \%$ \\
\hline UVI(Ho) & $-1.02 E+08$ & $9.89 \mathrm{E}+07$ & $13 \%$ & $22 \%$ \\
\hline AEI(Sys) & $1.25 \mathrm{E}+08$ & $1.38 \mathrm{E}+08$ & $42 \%$ & $38 \%$ \\
\hline AEI(Hvs) & $2.11 \mathrm{E}+06$ & $2.14 \mathrm{E}+06$ & $22 \%$ & $21 \%$ \\
\hline AEI(Ho) & $1.92 \mathrm{E}+07$ & $2.07 \mathrm{E}+07$ & $44 \%$ & $41 \%$ \\
\hline Rob(Sys) & 22.55 & 22.52 & $76 \%$ & $76 \%$ \\
\hline \multicolumn{3}{|c|}{ Aggregation of distances } & $235 \%$ & $265 \%$ \\
\hline \multicolumn{3}{|c|}{ Number of alternatives farther to Ideal } & 340 & 42 \\
\hline \multicolumn{3}{|c|}{ Number of alternatives closer to Ideal } & 159 & 23 \\
\hline \multicolumn{3}{|c|}{ Ratio farther/closer } & 2.14 & 1.83 \\
\hline
\end{tabular}




\section{Scenarios Module, D-ROSE:}

\begin{tabular}{lcccc} 
N(Scen_Vul) & 5 & 7 & $4 \%$ & $0 \%$ \\
N(Scen_Res ) & 16 & 16 & $87 \%$ & $93 \%$ \\
AltR & $7.59 \mathrm{E}+04$ & $7.12 \mathrm{E}+05$ & $7 \%$ & $5 \%$ \\
AltO & $1.99 \mathrm{E}+07$ & $1.99 \mathrm{E}+07$ & $97 \%$ & $97 \%$ \\
\hline- Aggregation of distances & & $194 \%$ & $195 \%$ \\
Number of alternatives farther to Ideal & & 64 & 8 \\
Number of alternatives closer to Ideal & & 1 & 1 \\
Ratio farther/closer & & 64 & 8 \\
\hline
\end{tabular}

$\left(^{*}\right)$ Planning module's "relevant" alternatives in the are the Scenarios module's "All" alternatives

Table 7 Comparison of the selected alternative with the sets of all and relevant alternatives

Table 7 also shows how the suitability of the selected alternative changes depending on whether it is evaluated in terms of planning or scenarios objectives. While the ratio of farther/closer alternatives in the first case was 1.83, in the case of scenario analysis this value, for the same set of alternatives, rose to 64 . This means that, although the selected alternative performance was only good in terms of the planning impact (23 closer alternatives), it performed much better in terms of risks and opportunities (1 closer alternative). The reason for choosing alternative 40 instead of alternative 56 (the closest to the ideal) is explained in section 4.2. Both of these, however, were suitable candidates, and illustrated the capabilities of this method, demonstrating its efficacy for identifying planning alternatives that are robust to risks, sensitive to windfalls and efficient in attaining the planning objectives.

As to the dynamic nature of many problems, in those regarding USP and UV this is present in both their temporal and socio-political dimensions (Salas \& Yepes, 2018a), which are sources of uncertainty that must be addressed. Regarding the time dynamics, on the one hand, the DAPP provides policy alternatives for overcoming contextual problems that may arise, at different moments (tipping points), along the development of an alternative/project. MS-ReRO, on the other hand, deals with the uncertainty attached to coordination problems when implementing alternatives through the multiple politicaladministrative scales of a system. Regarding trade-offs among short- and long-term temporal scales, MS-ReRO can be used in combination with methods already developed (Sierra et al., 2018b) for addressing this issue.

\section{Conclusions}

In pursuit of sustainable urban development, the improvement of UV is a key issue that is essential for urban management. This paper presented a comprehensive DSS for urban infrastructure planning that aims to cope with UV, integrating methods for the generation 
of both optimal plans and scenarios and their analysis, and proposing accompanying policy measures in a 3-step process following a discursive approach. The framework presented makes extensive use of visual analytics to conduct the discursive approach in a cognitive way, and implements two novel methods, the D-ROSE and the MS-ReRO, for scenario design and analysis, as presented in sections 2.3.2 and 2.3.3, and discussed in section 4.4.

Like methods based on scenario discovery (Bryant \& Lempert, 2010), the D-ROSE generates scenarios and identifies vulnerabilities as a function of SOWs that drive alternatives (plans) to extreme undesired values. The D-ROSE, however, also identifies windfall outcomes, enabling us to assess both the vulnerability and resilience of scenarios, from where risk and opportunity are derived. Another unique feature of the method presented lies in how the vulnerability and resilience criteria are applied. While in other methods the vulnerability (or resilience) criterion is set up ex ante, without deriving previous knowledge from the full set of scenarios, D-ROSE provides DMs with this knowledge by enabling them to dynamically set up the vulnerability and resilience criteria after extracting guidelines from previous sets of scenarios. From the set of relevant scenarios, D-ROSE derives, for each alternative, the associated risks and opportunities, improving the background available for an informed selection of planning alternatives. In this way, the DMs can choose planning alternatives that are robust to vulnerable scenarios and sensitive to resilient ones.

While D-ROSE takes into account the overall uncertainty borne by the system, MS-ReRO specifically focuses on the relational uncertainty arising from the system's multi-scale nature, and assesses the risks and opportunities attached to it. This enables us to propose optimal, ad hoc relational contracts as policy measures to accompany the investment plan selected (Frank \& Martínez-Vázquez, 2015).

As to the urban infrastructure planning module (section 2.2), the framework provides planners with a set of compromise solutions in which the impacts on both UV and economic costs are evaluated across the multiple scales of a territory (section 2.2.1), as well as the robustness against uncertainties attached to the costs of actions (section 2.2.3). Besides, stakeholders are represented as overall, high vulnerability and high opportunity interest groups (section 2.2.2). In this way, the method overcomes (Fig. 1) the limitations shown by other urban, such as AST, APST and IPSS, in the attainment of the characteristics demanded by USP (Table 1 ).

Then, the whole process was tested via a case study. For this purpose, Spain has been used as an example, and quantitative data on the city, province, region and country 
political-administrative scales were gathered. With this information, the process was performed, and the results showed that the method supports informed decision-making on UIPs evaluated under a set of relevant scenarios. In addition, the framework proposes policy actions, according to a desired trade-off between inter-scale relational risks and opportunities, to accompany the UIP selected in its implementation across politicaladministrative scales.

Despite the remarkable outcomes, there are still limitations to this study. While dealing with multi-scale dynamics, the framework revealed the shortcomings of a method such as DAPP when dealing with time-dependent planning dynamics. In addition to this, the scenarios module does not yet have a multi-objective capacity, though this should be attained in future research. Moreover, D-ROSE does not analyse the relations between the uncertainty variables that configure the scenarios and the vulnerable or resilient outcomes, which should again be the subject of future work. Finally, more research is needed for providing objective criteria on how to balance risks and opportunities, for example by examining the applicability of the anti-fragility concept (Taleb, 2018) in the selection of planning alternatives.

\section{Acknowledgments:}

The authors acknowledge the financial support of the Spanish Ministry of Economy and Competitiveness, along with FEDER funding (Project: BIA2017-85098-R).

\section{References}

Adger, W. N. (2006). Vulnerability. Resilience, Vulnerability, and Adaptation: A CrossCutting Theme of the International Human Dimensions Programme on Global Environmental Change Resilience, Vulnerability, and Adaptation: A Cross-Cutting Theme of the International Human Dimensions Programme, 16(3), 268-281. http://doi.org/http://dx.doi.org/10.1016/j.gloenvcha.2006.02.006

Ben-Haim, Y. (2006). Info-Gap Decision Theory (Second Edition) (Second Edition, pp. 1-8). Oxford: Academic Press. http://doi.org/https://doi.org/10.1016/B978$\underline{012373552-2 / 50002-3}$

Brown, C., Werick, W., Leger, W., \& Fay, D. (2011.). A Decision-Analytic Approach to Managing Climate Risks: Application to the Upper Great Lakes1. JAWRA 
Journal of the American Water Resources Association, 47(3), 524-534.

http://doi.org/10.1111/j.1752-1688.2011.00552.x

Bryant, B. P., \& Lempert, R. J. (2010). Thinking inside the box: A participatory, computer-assisted approach to scenario discovery. TECHNOLOGICAL FORECASTING AND SOCIAL CHANGE, 77(1), 34-49. http://doi.org/10.1016/j.techfore.2009.08.002

Charbit, C., \& Gamper, C. (2015). Coordination of infrastructure investment across levels of government. Decentralization and Infrastructure in the Global Economy: From Gaps to Solutions. http://doi.org/10.4324/9781315694108

Charbit, C. \& Michalun, M. (2009), Mind the gaps: Managing Mutual Dependence in Relations among Levels of Government, OECD Working Papers on Public Governance, No. 14. OECD Publishing. http://doi:10.1787/221253707200

Dessai, S., \& Hulme, M. (2004). Does climate adaptation policy need probabilities? Climate Policy. Retrieved from http://www.scopus.com/inward/record.url?eid=2$\underline{\text { s2.0-14644438513\&partnerID=tZOtx3y1 }}$

Encuesta de Infraestructura y Equipamientos Locales (EIEL), (2003). Retrieved 09/22/2017 from:

http://www.seat.mpr.gob.es/en/portal/areas/politica_local/coop_econom_local_estado_f ondos_europeos/eiel/consulta_descarga_datos_2000_2005_2008_2009_2010-y-

2011.html

Eusgeld, I., Nan, C., \& Dietz, S. (2011). “System-of-systems” approach for interdependent critical infrastructures. Reliability Engineering \& System Safety, 96(6), 679-686. http://doi.org/https://doi.org/10.1016/j.ress.2010.12.010

Frank, J., \& Martínez-Vázquez, J. (2015). Decentralization and infrastructure in the global economy: From gaps to solutions. Decentralization and Infrastructure in the Global Economy: From Gaps to Solutions.

http://doi.org/10.4324/9781315694108

Haasnoot, M., Kwakkel, J. H., Walker, W. E., \& ter Maat, J. (2013). Dynamic adaptive policy pathways: A method for crafting robust decisions for a deeply uncertain 
world. Global Environmental Change, 23(2), 485-498.

http://doi.org/10.1016/j.gloenvcha.2012.12.006

Hadka, D., Herman, J., Reed, P., \& Keller, K. (2015). An open source framework for many-objective robust decision making. Environmental Modelling \& Software, 74(Supplement C), 114-129.

http://doi.org/https://doi.org/10.1016/j.envsoft.2015.07.014

Hermeling, C., Löschel, A., \& Mennel, T. (2013). A new robustness analysis for climate policy evaluations: A CGE application for the EU 2020 targets. Energy Policy, 55, 27-35. http://doi.org/10.1016/j.enpol.2012.08.007

Hurtado, S. D. G. (2017). Is EU urban policy transforming urban regeneration in Spain? Answers from an analysis of the Iniciativa Urbana (2007-2013). Cities, 60, 402414. http://doi.org/https://doi.org/10.1016/j.cities.2016.10.015

Hurtado, S. D. G. (2012). Políticas urbanas de la Unión Europea desde la perspectiva de la Planificación Colaborativa. Las Iniciativas Comunitarias URBAN y URBAN II en España. PhD thesis Departamento de Urbanística y Ordenación del Territorio, Escuela Técnica Superior de Arquitectura, Universidad Politécnica de Madrid. http://oa.upm.es/12740/1/SONIA_DE_GREGORIO_HURTADO.pdf

Johansson, J., \& Hassel, H. (2010). An approach for modelling interdependent infrastructures in the context of vulnerability analysis. Reliability Engineering \& System Safety, 95(12), 1335-1344. http://doi.org/https://doi.org/10.1016/j.ress.2010.06.010

Kasprzyk, J. R., Nataraj, S., Reed, P. M., \& Lempert, R. J. (2013). Many objective robust decision making for complex environmental systems undergoing change. Environmental Modelling \& Software, 42, 55-71. http://doi.org/https://doi.org/10.1016/j.envsoft.2012.12.007

King, R. A. R., \& Blackmore, K. L. (2013). Physical and political boundaries as barriers to the continuity of social vulnerability. Applied Geography, 44, 79-87. http://doi.org/http://dx.doi.org/10.1016/j.apgeog.2013.07.011 
Lempert, R. J. (2002). A new decision sciences for complex systems. Proceedings of the National Academy of Sciences of the United States of America, 99(SUPPL. 3), 7309-7313. http://doi.org/10.1073/pnas.082081699

Lempert, R. J., Groves, D. G., Popper, S. W., \& Bankes, S. C. (2006). A General, Analytic Method for Generating Robust Strategies and Narrative Scenarios. Management Science, 52(4), 514-528. http://doi.org/10.1287/mnsc.1050.0472

Liao, T. W., Egbelu, P. J., Sarker, B. R., \& Leu, S. S. (2011). Metaheuristics for project and construction management - A state-of-the-art review. Automation in Construction, 20(5), 491-505.

http://doi.org/http://dx.doi.org/10.1016/j.autcon.2010.12.006

Ma, J., \& Hipel, K. W. (2016). Exploring social dimensions of municipal solid waste management around the globe - A systematic literature review. Waste Management, 56, 3-12. http://doi.org/https://doi.org/10.1016/j.wasman.2016.06.041

Malekpour, S., Brown, R. R., \& de Haan, F. J. (2015). Strategic planning of urban infrastructure for environmental sustainability: Understanding the past to intervene for the future. Cities, 46, 67-75.

Martí, J. V, García-Segura, T., \& Yepes, V. (2016). Structural design of precastprestressed concrete U-beam road bridges based on embodied energy. Journal of Cleaner Production, 120, 231-240. article. http://doi.org/http://doi.org/10.1016/j.jclepro.2016.02.024

Mejia Dorantes, L., Paez, A., \& Manuel Vassallo, J. (2011). Analysis of House Prices to Assess Economic Impacts of New Public Transport Infrastructure Madrid Metro Line 12. TRANSPORTATION RESEARCH RECORD, (2245), 131-139. http://doi.org/10.3141/2245-16

Menoni, S., \& Pergalani, F. (1994). An attempt to link risk assessment with land use planning: A recent experience in Italy. Disaster Prevention and Management: An International Journal, 5(1), 6-21. Retrieved from https://www.scopus.com/inward/record.uri?eid=2-s2.00141915141\&partnerID=40\&md5=8c7560802687eec051b8ff9047688119 
Nahiduzzaman, K. M., Aldosary, A. S., \& Rahman, M. T. (2015). Flood induced vulnerability in strategic plan making process of Riyadh city. Habitat

International, 49, 375-385. http://doi.org/10.1016/j.habitatint.2015.05.034

Nguyen, T. P. K., Beugin, J., \& Marais, J. (2015). Method for evaluating an extended Fault Tree to analyse the dependability of complex systems: Application to a satellite-based railway system. Reliability Engineering \& System Safety, 133, 300 313. http://doi.org/https://doi.org/10.1016/j.ress.2014.09.019

Organization for Economic Cooperation and Developement (OECD), (2007). Linking regions and central governments: Contracts for regional development. Linking Regions and Central Governments: Contracts for Regional Development (Vol. 9789264008755). http://doi.org/10.1787/9789264008755-en

Prudhomme, C., Wilby, R. L., Crooks, S., Kay, A. L., \& Reynard, N. S. (2010). Scenario-neutral approach to climate change impact studies: Application to flood risk. Journal of Hydrology, 390(3), 198-209.

http://doi.org/https://doi.org/10.1016/j.jhydrol.2010.06.043

Ray, P. A.; Brown, C. M. (2015). Confronting climate uncertainty in water resources planning and project design : the decision tree framework (English). Washington, D.C. : World Bank Group. http://documents.worldbank.org/curated/en/516801467986326382/Confrontingclimate-uncertainty-in-water-resources-planning-and-project-design-the-decisiontree-framework

Salas, J., \& Yepes, V. (2018a). Urban vulnerability assessment: Advances from the strategic planning outlook. Journal of Cleaner Production, 179, 544-558. http://doi.org/10.1016/j.jclepro.2018.01.088

Salas, J., \& Yepes, V. (2018b). A discursive, many-objective approach for selecting more-evolved urban vulnerability assessment models. Journal of Cleaner Production, 176, 1231-1244. https://doi.org/10.1016/j.jclepro.2017.11.249

Schweikert, A., Chinowsky, P., Kwiatkowski, K., \& Espinet, X. (2014). The infrastructure planning support system: Analyzing the impact of climate change on road infrastructure and development. Transport Policy, 35, 146-153. http://doi.org/https://doi.org/10.1016/j.tranpol.2014.05.019 
Sierra, L. A., Yepes, V., \& Pellicer, E. (2018a). A review of multi-criteria assessment of the social sustainability of infrastructures. Journal of Cleaner Production, 187, 496-513. http://doi.org/https://doi.org/10.1016/j.jclepro.2018.03.022

Sierra Varela, L., Yepes, V., García-Segura, T., \& Pellicer, E. (2018b). Bayesian network method for decision-making about the social sustainability of infrastructure projects. Journal of Cleaner Production, 176, 521-534.

Sierra, L. A., Yepes, V., \& Pellicer, E. (2017). Assessing the social sustainability contribution of an infrastructure project under conditions of uncertainty. Environmental Impact Assessment Review, 67, 61-72. http://doi.org/https://doi.org/10.1016/j.eiar.2017.08.003

Stern, P. C., Ebi, K. L., Leichenko, R., Olson, R. S., Steinbruner, J. D., \& Lempert, R. (2013). Managing risk with climate vulnerability science. Nature Climate Change, 3(7), 607-609. http://doi.org/10.1038/nclimate1929

Taylor, M. A. P., Sekhar, S. V. C., \& D’Este, G. M. (2006). Application of accessibility based methods for vulnerability analysis of strategic road networks. Networks and Spatial Economics, 6(3-4), 267-291. http://doi.org/10.1007/s11067-006-9284-9

Taleb, N. N. (2018). (Anti)Fragility and Convex Responses in Medicine. In Springer Proceedings in Complexity (pp. 299-325). http://doi.org/10.1007/978-3-31996661-8_32

van de Ven, F. H. M., Snep, R. P. H., Koole, S., Brolsma, R., van der Brugge, R., Spijker, J., \& Vergroesen, T. (2016). Adaptation Planning Support Toolbox: Measurable performance information based tools for co-creation of resilient, ecosystem-based urban plans with urban designers, decision-makers and stakeholders. Environmental Science and Policy, 66, 427-436.

http://doi.org/10.1016/j.envsci.2016.06.010

Video 1: https://www.youtube.com/watch?v=8ly0mgYjXtI

Video 2: https://www.youtube.com/watch?v=_6jMJLVTtt4

Video 3: https://www.youtube.com/watch?v=Pxkr2qaiynU 
Voskamp, I. M., \& de Ven, F. H. M. (2015). Planning support system for climate adaptation: Composing effective sets of blue-green measures to reduce urban vulnerability to extreme weather events. Building and Environment, 83, 159-167. http://doi.org/10.1016/j.buildenv.2014.07.018

Yepes, V., García-Segura, T., \& Moreno-Jiménez, J. M. (2015). A cognitive approach for the multi-objective optimization of RC structural problems. Archives of Civil and Mechanical Engineering, 15(4), 1024-1036. http://doi.org/10.1016/j.acme.2015.05.001 


\section{List of Tables}

Table 1. Characteristics demanded for an effective urban strategic planning

Table 2. Table 2: Investment on URBAN programs and ERDF support allocation

Table 3. Characteristics of bottom-up decision support systems

Table 4. Infrastructure variables and planning actions

Table 5. Problem formulation, variables and framework results

Table 6. Asymmetry index by regions

Table 7: Comparison of the selected alternative with the sets of all and relevant alternatives

\section{List of Figures}

Figure. 1. General workflow and case study

Figure. 2. Detailed workflow of the planning system and case study

Figure. 3. Bottom-up propagation through multi-scale hierarchical systems

\section{List of Videos}

Video. 1. Selection of relevant UIP

https://www.youtube.com/watch?v=8ly0mgYjXtl

Video. 2. Selection of relevant scenarios and planning alternatives from D-ROSE https://www.youtube.com/watch?v= 6jMJLVTtt4

Video. 3. Selection of accompanying policy alternatives from clustered group https://www.youtube.com/watch?v=Pxkr2qaiynU 